\title{
A importância das cadeias da cana-de-açúcar: uma análise insumo-produto
}

\author{
Augusto Frederico Maia Soares Silva ${ }^{1}$ \\ Guilherme Nascimento Gomes ${ }^{2}$ \\ Mirian Rumenos Piedade Bacchi ${ }^{3}$
}

\begin{abstract}
Resumo: 0 objetivo deste artigo é analisar o impacto que teria uma estagnação do setor de cana-de-açúcar no Brasil. Em específico, busca-se estudar, por meio do modelo de insumo-produto, pelo método de extração hipotética setorial, o qual se fundamenta na hipótese do desaparecimento de um determinado setor, o grau de dependência para trás e para frente e os impactos nos demais setores. 0 estudo foi feito considerando dados do ano de 2013. Os principais resultados revelam grande impacto em nível nacional com redução significativa de $0,93 \%$ do produto quando comparado à extração de setores de relevância.
\end{abstract}

Palavras-chave: Cana-de-açúcar. Insumo-Produto. Método de Extração Hipotética.

Classificação JEL: C67, Q19.

\section{The importance of sugar cane chains: an input-output analysis}

\begin{abstract}
The objective of this paper is to analyze the impact of the sugarcane sector stagnation on Brazilian economy. Specifically, this paper evaluates the backward and forward linkages and the impact of sugarcane sector on other sectors, using InputOutput model and applying the hypothetical extraction method, which is based on hypothetically removing a sector from the economic system. It uses the Brazilian InputOutput matrix for 2013. The main results show a great impact on Brazilian economy and a substantial reduction of $0.93 \%$ aggregate output when compared to the extraction of important sectors.
\end{abstract}

Keywords: Sugarcane. Input-Output. Hypothetical Extraction Method.

1 Bacharel em Ciências Econômicas pela Esalq/USP. E-mail: augustofmg@gmail.com

2 Mestre em Economia Aplicada pela UFSCar e Doutorando em Política Científica e Tecnológica pela UNICAMP.E-mail: guingomes@gmail.com

3 Professora Titular do Departamento de Economia, Administração e Sociologia da Escola Superior de Agricultura "Luiz de Queiroz" da USP (Esalq/USP). E-mail: mrpbacch@usp.br 


\section{Introdução}

O complexo canavieiro brasileiro ocupa posição privilegiada entre os setores-chaves do país, uma vez que ele possui influências em questões sociais (emprego, uso da terra e segurança alimentar), ambientais (qualidade do ar e do solo, uso da água e biodiversidade) e econômicas (segurança energética, balanço de pagamentos e inflação).

A participação do setor canavieiro no PIB brasileiro aumentou entre 2008 e 2010 , passando de $2,68 \%$ para $3,67 \%$. Contudo, tem-se observado, nos últimos anos, uma queda dessas taxas, sendo que, em 2014, a participação foi de 2,06\%. Dentre os fatores responsáveis pela estagnação da área plantada estão, entre outros: alto custo do capital para investimentos, falta de sinalização do governo para a inserção do etanol na matriz energética nacional, descapitalização do setor pela concorrência não justa com o preço da gasolina que se manteve artificialmente baixo por muitos anos.

Em um estudo sobre o neocorporativismo na cadeia da cana-de-açúcar, Shikida et al. (2004) evidenciam que as dificuldades citadas acima cresceram devido ao afastamento do Estado, às limitações institucionais e à complexidade da cadeia. Dessa maneira, a conciliação dos interesses dos agentes da própria cadeia produtiva, das outras que se inter-relacionam e da sociedade se tornou um desafio a ser contornado para retornar aos rumos do crescimento.

Segundo Bacchi e Caldarelli (2015), a atividade canavieira, no contexto do agronegócio, apresenta significativa importância para a economia nacional e justifica a análise de externalidades a essa atividade relacionadas, podendo auxiliar no processo de definição de políticas públicas e setoriais. Dessa forma, a partir da expectativa de estagnação da produção canavieira, faz-se necessária uma análise aprofundada dos setores associados. Vale ainda ressaltar que são setores que fazem parte da matriz energética brasileira e de baixo custo de aquisição.

0 modelo analítico desenvolvido por Leontief sobre a estrutura de insumoproduto evidencia e descreve as interdependências (pelas óticas da compra e da venda) entre os setores de uma nação (estado ou região) em um determinado ponto no tempo (normalmente um ano) (MILLER; BLAIR, 2009, p. 10-11). Para analisar as interligações setoriais na economia brasileira, propõe-se utilizar o método de extração hipotética aplicado à matriz insumo-produto brasileira para o ano de 2013. 0 método proposto por Dietzenbacher, Linden e Steenge (1993) foi utilizado a fim de quantificar as interdependências setoriais entre os países da comissão europeia para os anos de 1970 e de 1980 como uma proposta complementar aos índices de Hischman (1958).

Assim, o objetivo deste artigo é analisar os impactos da estagnação da cadeia de cana-de-açúcar (por meio de dados secundários) buscando aplicar o método de extração hipotética setorial utilizando a abordagem de insumo-produto. Portanto, 
se levanta a hipótese de desaparecimento de um determinado setor para analisar os impactos e o grau de dependência para trás e para frente de outros setores da economia.

O presente trabalho está organizado em três seções, além desta introdução e da conclusão. A seção seguinte trata de aspectos teóricos. Na terceira, faz-se uma análise da trajetória e características do setor. Na quarta, apresentam-se os conceitos metodológicos utilizados neste trabalho. Na quinta, os principais resultados da análise de insumo-produto são apresentados, além dos resultados do método de extração hipotética.

\section{A produção da cana-de-açúcar e seus impactos: recuperando aspectos} teóricos da literatura

De acordo com Bacchi (2009), o Brasil é o maior produtor de cana-de-açúcar do mundo, propiciando a produção de açúcar - fonte energética da alimentação do brasileiro - e de etanol, combustível que gera menos impactos que os fósseis no ambiente. A autora ressalta que o etanol proveniente da cana-de-açúcar é mais eficiente que os renováveis produzidos a partir de outras culturas como milho, mandioca, beterraba e sorgo.

Chagas (2009) destaca o Brasil como um dos países mais avançados na busca por fontes energéticas limpas. A competitividade do etanol produzido a partir da cana-de-açúcar frente a outras fontes energéticas renováveis desenvolvidas ao redor do mundo é um dos fatores relevantes para isso. Em busca de uma produção socioambiental mais sustentável, foi firmado em 2007, o Protocolo Agroambiental do Setor Sucroenergético. Nele, ficaram definidas metas a serem alcançadas para a substituição da colheita manual pela mecanizada, buscando reduzir as emissões de $\mathrm{CO}_{2}$ provenientes das queimadas durante a colheita. 0 protocolo foi assinado pela Secretaria de Meio Ambiente, Secretaria da Agricultura e Abastecimento de São Paulo, União da Indústria de Cana-de-Açúcar e Organização de Plantadores de Cana da Região Centro-Sul do Brasil.

Bacchi e Caldarelli (2015) discutem a importância do setor sucroalcooleiro e como a produção sustentável de etanol pode representar uma oportunidade para nações em desenvolvimento. Nesse estudo, os autores comprovam, através de um modelo em que se utiliza dados em painel para o estado de São Paulo, que a população residente nas proximidades das unidades produtoras de cana, seja para açúcar, etanol ou eletricidade, obtém ganhos nos quesitos renda e emprego. A utilização de São Paulo na análise se dá por representar mais da metade da produção de cana no Brasil.

Hoffmann (2006) também mostra que o aumento da produção de etanol representa crescimento econômico com geração de empregos e renda. Por meio 
de uma análise de dados da Pesquisa Nacional por Amostra de Domicílios (PNAD), o autor identifica que a baixa renda domiciliar per capita e a escolaridade dos indivíduos são os principais fatores que influenciam na insegurança alimentar no Brasil. Dessa maneira, os ganhos com a geração de empregos e renda provenientes do desenvolvimento sucroalcooleiro devem auxiliar a população brasileira. Esses resultados são significativos mesmo em um cenário em que algum efeito negativo, como um possível aumento nos preços de alimentos causado pela competição por áreas cultiváveis, possa ocorrer.

Buscando avaliar o impacto da produção da cana-de-açúcar em detrimento da produção de alimentos, Chagas et al. (2008) avaliaram os potenciais impactos da expansão da produção de cana-de-açúcar sobre o preço da terra e dos alimentos. Sobre a ótica da segurança alimentar, os autores concluíram que não existe causalidade no sentido de Granger entre produção de cana-de-açúcar e preço de terra e de alimento.

Na próxima seção, busca-se caracterizar os diferentes setores do complexo da cana-de-açúcar no Brasil.

\section{Cadeias da cana-de-açúcar}

De acordo com os dados do Relatório do Centro de Estudos Avançados em Economia Aplicada (CEPEA-Esalq/USP) e da Confederação Nacional da Agricultura (CNA, 2017), o PIB da cadeia da cana-de-açúcar foi de 120,4 bilhões de reais em 2014, medido a preços constantes de 2015 (Gráfico 1). 0 setor vem apresentando tendência de queda no PIB real da cadeia desde 2010. Nesse sentido, a cadeia da cana-de-açúcar foi responsável por 2,06\% do PIB total do país, a participação está em declínio desde o "boom" do setor em 2005/2006, com sensível melhora nos anos de 2009/2010. 
Gráfico 1: PIB das cadeias da cana-de-açúcar brasileiro a preços de 2015 (em bilhões) e participação do PIB da cana-de-açúcar no PIB total do Brasil (\%)

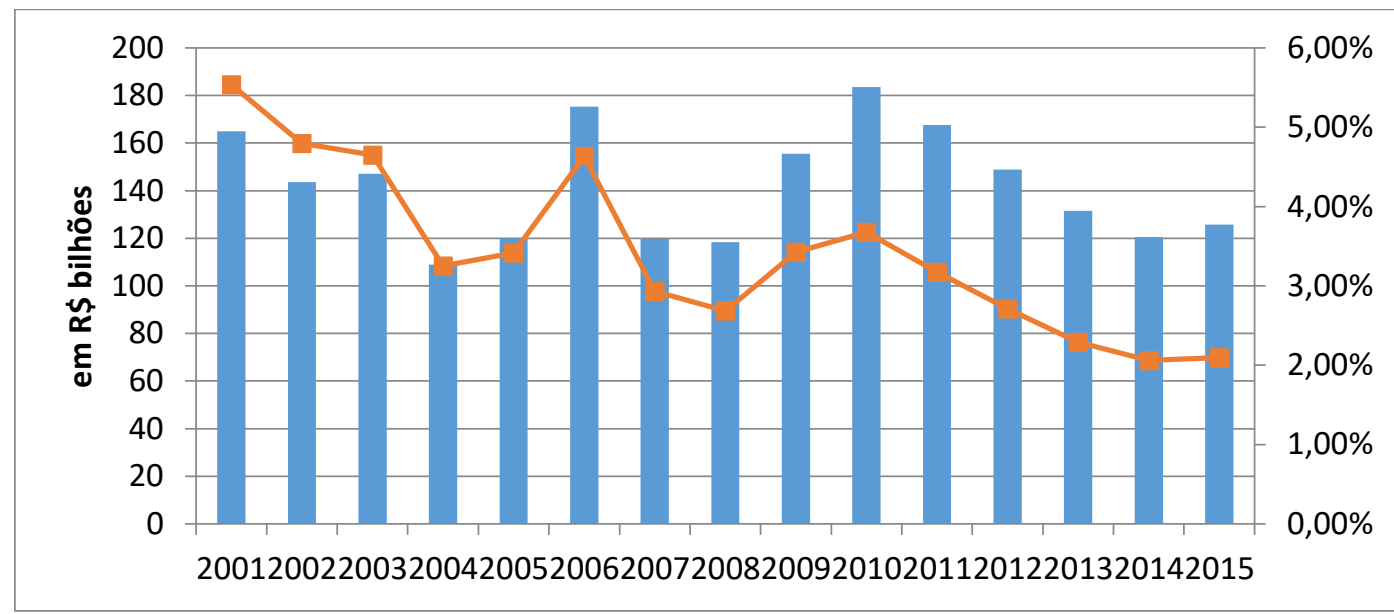

Nota: PIB da cadeia da cana-de-açúcar deflacionado pelo IPCA.

Fonte: elaboração própria a partir de dados do CEPEA, CNA e IBGE

De acordo com o Instituto Brasileiro de Geografia e Estatística (IBGE), a área cultivável total do país é de 851,6 milhões de hectares. Exclui-se a ocupação aquática (5,5 milhões de hectares) e aproximadamente 846,1 milhões de hectares são de áreas terrestres. 0 acompanhamento de safra da Companhia Nacional de Abastecimento (CONAB) estimou que, para a safra $(2015 / 2016)$, cerca de 9,0 milhões de hectares seriam dedicados à cana-de-açúcar, o que representa um crescimento de $54 \%$ no comparativo com a safra 2005/2006. A União da Indústria de Cana-de-açúcar (UNICA) estima que, desse total, $52 \%$ está localizado no estado de São Paulo, região de maior predominância da cultura.

Assim, a área destinada à cultura no país corresponde a pouco mais de $1,1 \%$ da área total, montante considerado baixo, dada a relevância da cultura para a economia nacional. Segundo os dados da CONAB, a área plantada de cana-de-açúcar cresceu de maneira intensa durante a última década.

Como lembra Chagas (2009), esse "boom" do setor canavieiro se deu por meio das transformações intensas que vão desde atração de capital externo, construção de novas plantas industriais para processamento da matéria-prima e intensificação dos processos de fusões e de aquisições no setor. Pode-se somar a isso, o incentivo às montadoras para a produção dos carros flex, que reforçaram o avanço da cultura da cana-de-açúcar no país.

Realizando um comparativo com as principais culturas dedicadas ao fornecimento de alimentos, a participação da cana-de-açúcar no total da área plantada cresceu durante os últimos anos. Considerando as maiores culturas 
(algodão, amendoim, arroz, aveia, canola, centeio, cevada, feijão, girassol, mamona, milho, soja, sorgo, trigo e triticale), a participação da área ocupada de cana-de-açúcar aumentou de $10,9 \%$ na safra de $2005 / 2006$ para $13,3 \%$ na safra $2015 / 2016$. Porém, desde a safra de 2011/2012, a participação da cana-de-açúcar tem recuado (Tabela 1).

Na competição com os outros segmentos de grande importância na geração de alimentos, como a pecuária, a área dedicada à cultura da cana é, ainda, relativamente pequena. Segundo estimativas da Scot Consultoria e do IBGE, a área brasileira utilizada com pastagem, em 2015, foi de 163,58 milhões de hectares (Tabela 2). Dessa maneira, embora a área ocupada pela cana-de-açúcar venha crescendo e a área ocupada com pastagens diminuindo, a cana ainda representa uma parcela considerada baixa se comparada à pecuária, em torno de 5,5\%.

Tabela 1: Área destinada à produção das principais culturas alimentícias e à produção de cana-de-açúcar (2005-2016)

\begin{tabular}{|c|c|c|c|c|c|c|c|c|c|c|c|}
\hline \multirow[t]{2}{*}{ Produto/Safra } & $2005 / 0$ & $2006 / 0$ & $2007 / 0$ & $2008 / 0$ & $2009 / 1$ & $2010 / 1$ & $2011 / 1$ & $2012 / 1$ & $2013 / 1$ & $2014 / 1$ & $2015 / 16(p)$ \\
\hline & 6 & 7 & 8 & 9 & 1 & 1 & 2 & 3 & 4 & 5 & \\
\hline $\begin{array}{l}\text { Principais culturas } \\
\text { (a) }\end{array}$ & \multicolumn{10}{|c|}{ (a) } & 67,40 \\
\hline Cana-de-açúcar (b) & 5,80 & 6,20 & 7,00 & 7,10 & 7,40 & 8,10 & 8,40 & 8,50 & 8,80 & 9,00 & 9,00 \\
\hline \multirow[t]{2}{*}{ (b)/(a) } & 10,90 & 11,80 & 12,90 & 12,90 & 13,50 & 13,90 & 14,10 & 13,70 & 13,40 & 13,40 & $13,30 \%$ \\
\hline & $\%$ & $\%$ & $\%$ & $\%$ & $\%$ & $\%$ & $\%$ & $\%$ & $\%$ & $\%$ & \\
\hline
\end{tabular}

Tabela 2: Área destinada à pastagem (pecuária) e à produção de cana-de-açúcar (2005-2016)

\begin{tabular}{cccccccccccc}
\hline Produto/Safra & $2005 / 0$ & $2006 / 0$ & $2007 / 0$ & $2008 / 0$ & $2009 / 1$ & $2010 / 1$ & $2011 / 1$ & $2012 / 1$ & $2013 / 1$ & $2014 / 1$ & $2015 / 16(\mathrm{p})$ \\
& 6 & 7 & 8 & 9 & 1 & 1 & 2 & 3 & 4 & 5 & \\
\hline Pastagem (a) & 160,04 & 165,89 & 171,74 & 171,35 & 170,32 & 168,96 & 167,61 & 166,59 & 165,58 & 164,58 & 163,58 \\
Cana-de-açúcar(b) & 5,84 & 6,16 & 7,01 & 7,06 & 7,41 & 8,06 & 8,36 & 8,49 & 8,81 & 9,00 & 9,00 \\
(b)/(a) & $3,60 \%$ & $3,70 \%$ & $4,10 \%$ & $4,10 \%$ & $4,40 \%$ & $4,80 \%$ & $5,00 \%$ & $5,10 \%$ & $5,30 \%$ & $5,50 \%$ & $5,50 \%$ \\
\hline
\end{tabular}

Nota: $\mathrm{p}$ - previsão

Fonte: Scot Consultoria, IBGE e CONAB, elaborado pelos autores. 
Apesar da pouca área utilizada na comparação com outras culturas e atividades, atualmente, o Brasil é o maior produtor de cana-de-açúcar do mundo. Em 2012, foram 594,3 milhões de toneladas produzidas, o que garantiu o primeiro lugar com 32,4\% de representatividade. A Índia e a China foram responsáveis por 19,0\% e 6,7\%, respectivamente, da produção mundial de cana, com 347,9 e 123,5 milhões de toneladas, respectivamente. Com exceção desses países, todas as outras nações do globo produziram juntas 766,8 milhões de toneladas, o equivalente a $41,8 \%$ do total (Gráfico 2). Para a safra (2015/2016), eram esperadas 655,2 milhões de toneladas, um incremento de 3,2\% frente à safra imediatamente anterior. 0 Brasil deverá continuar como o maior produtor mundial dessa cultura.

Gráfico 2: Share da produção mundial de cana-de-açúcar (\%) e da produção brasileira (em milhões de toneladas) (2003-2012)

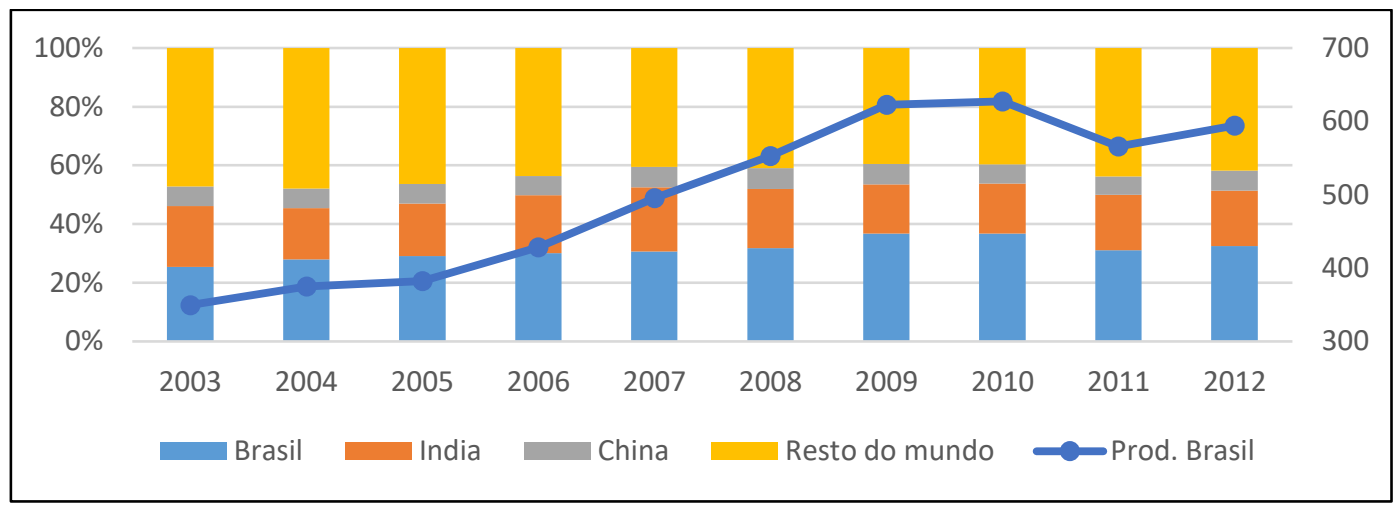

Fonte: elaboração própria a partir de dados do CONAB e FAO (2015)

Desde a safra 2006/2007, com a consolidação da produção e vendas dos carros flex, o etanol vem sendo responsável por utilizar a maior parte da produção total de cana-de-açúcar no Brasil (655,2 milhões de toneladas). Segundo dados do último acompanhamento da safra brasileira de cana-de-açúcar, elaborado pela CONAB, no período 2015/2016, 366,1 milhões de toneladas (ou 55,9\% do todo) foram destinadas à produção de etanol, enquanto 289,1 milhões $(44,1 \%)$ foram utilizadas para a produção de açúcar (Gráfico 3).

Dessa forma, pode-se concluir (considerando que 55,9\% da matéria-prima do ano-safra 2015/2016 são destinadas à fabricação do etanol) que foram utilizados 5,02 milhões de hectares para a fabricação do combustível, menos de 2,5\% da área destinada à pecuária e grãos em conjunto. Para a produção de açúcar, foram destinados 1,9\% dos 222,04 milhões de hectares utilizados no cultivo de grãos e na pecuária. 
Gráfico 3: Evolução da produção de cana-de-açúcar destinada à produção de etanol e de açúcar (em milhões de toneladas) (2005-2016)

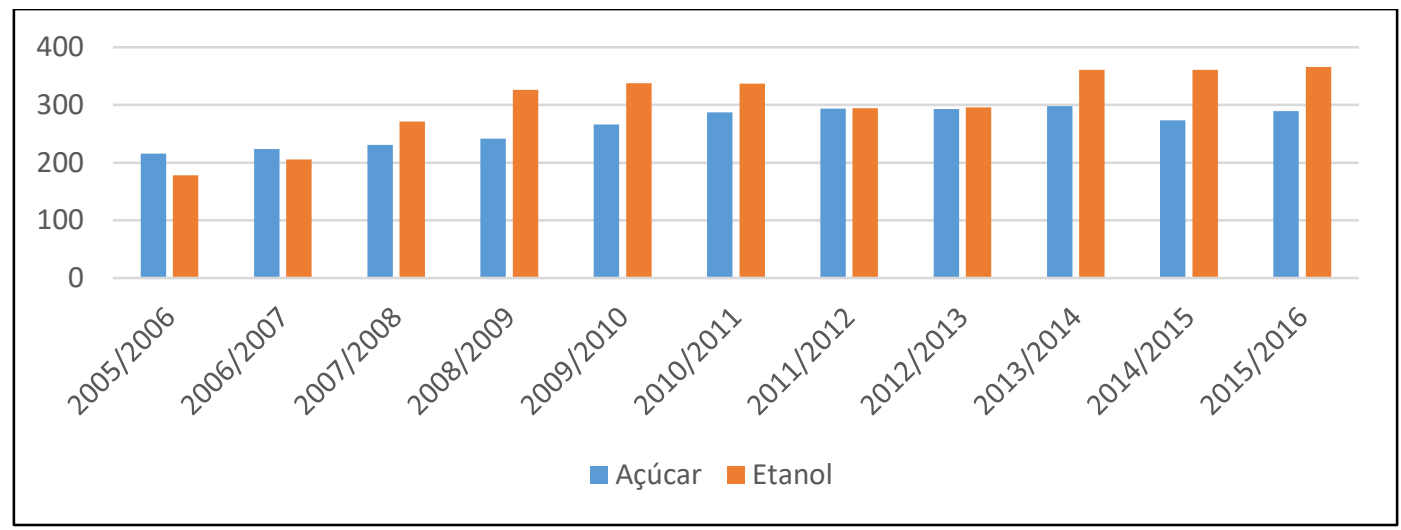

Fonte: elaboração própria a partir de dados da CONAB (2015).

No Gráfico 4, pode-se observar que apesar da maior parte da área colhida de canade-açúcar ser destinada à produção de etanol, na safra 2015/2016, foram produzidas 34,6 milhões de toneladas de açúcar e 29,2 milhões de litros de etanol no total, sendo 11,0 milhões do anidro e 18,2 milhões do hidratado4. Desde a safra 2005/2006 até a 2014/2015, a produção de etanol hidratado, que foi de 7,7 milhões de litros, cresceu $134,8 \%$. Já a produção de etanol anidro, de 9,1\% na safra 2005/2006, aumentou para $21,1 \%$ no período em questão. No caso do açúcar, o crescimento foi de aproximadamente $30 \%$.

Apesar de ser o maior produtor mundial de cana-de-açúcar, o Brasil é superado na produção de etanol pelos Estados Unidos da América (EUA). Isso acontece mesmo sendo a produção de etanol norte-americana originada da cultura do milho, considerada menos eficiente que a da cana-de-açúcar. Segundo pesquisas da Renewable Fuels Association (RFA), em 2014, os EUA produziram 14,3 milhões de galões de etanol, seguidos do Brasil (6,2 milhões), da Europa (1,4 milhões) e do restante do mundo (2,6 milhões de galões). A participação desses países/continentes no total produzido mundialmente foi de $58,2 \%$, $25,2 \%, 5,9 \%$ e $10,7 \%$, respectivamente.

Nos últimos anos, porém, o setor está passando por um momento de estagnação, resultado de uma crise causada pela elevação dos custos de produção e

40 etanol hidratado, usado como combustível substituto da gasolina, apresenta concentração de $96 \%$; o etanol anidro, usado como aditivo na gasolina, cerca de 99,5 \%, necessitando etapas suplementares de destilação (MILANEZ et al. 2012). 
da concorrência com os preços controlados da gasolina (GIGLIO, 2015), dentre outros fatores. A CONAB cita ainda que a crescente necessidade de capital financeiro para a formação de estoques de etanol e de açúcar são problemas que, somados às baixas remunerações das últimas safras, vêm causando a crise do setor.

Gráfico 4: Evolução da produção de etanol, soma do anidro e hidratado e da produção de açúcar (em milhões de litros e toneladas, respectivamente) (20052016)

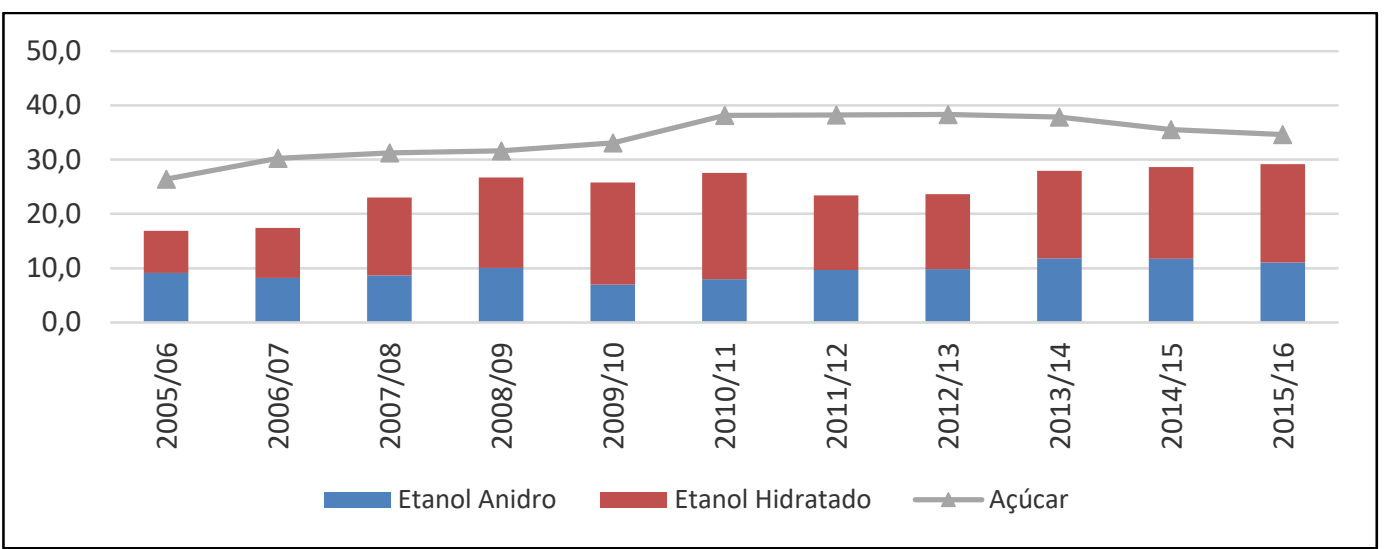

Fonte: elaboração própria a partir de dados da CONAB (2015).

Milanez et al. (2012) argumentam existir um descompasso entre a oferta e a demanda do etanol carbureto, resultado de um déficit da produção desse biocombustível desde 2012. Houve estagnação da oferta do etanol, no período entre 2008 e 2010, que não acompanhou a demanda potencial impulsionada pela venda de automóveis flex. Os determinantes relevantes para a estagnação da produção de etanol se deve, em parte, à redução da capacidade de investimento do setor.

Os principais grupos econômicos do setor se endividaram entre 2003 e 2008, em alguns casos em moeda estrangeira, o que foi resultante de uma propensão ao crescimento, motivado pela expectativa de que o etanol se tornaria uma commodity com grande representatividade no mercado internacional. Contudo, a crise financeira de 2008 fez com que a capacidade de investimento do setor se deteriorasse (MILANEZ et al., 2012). Os autores também argumentam que outro fator para a estagnação é a rentabilidade limitada do etanol hidratado, uma vez que os produtores raramente conseguem remuneração acima de seus custos, apresentando fragilidades do setor.

Os principais resultados e indicadores do setor mostram aumento da produção nos últimos anos, contudo tem se observado a grande fragilidade do setor sucroalcooleiro no Brasil, dada a falta de uma política de longo prazo para combustíveis renováveis no Brasil e pelos preços praticados serem pouco remuneradores. 
Na próxima seção, são apresentados os aspectos metodológicos utilizados no estudo a fim de atingir os objetivos propostos. A seguinte seção versa sobre a hipótese de desaparecimento do setor, uma vez que o declínio gradual ou acelerado da produção pode levar à perda de vantagens comparativas, fazendo com que ele desapareça ou passe ter menos expressão na economia. 0 método utilizado auxilia a compreender a importância dos setores da cana-de-açúcar para a economia brasileira e os impactos advindos do seu desaparecimento.

\section{Metodologia}

Esta seção objetiva descrever a metodologia e a base de dados utilizada neste trabalho com o intuito de gerar informações que possibilitem compreender os setores da cadeia da cana-de-açúcar e seus impactos nos outros setores da economia. Dessa maneira, optou-se por utilizar o método de extração hipotética setorial que permite quantificar como a produção total de uma economia com $n$-setores mudaria (reduziria) se um determinado setor (j-ésimo) fosse removido dessa economia (MILLER; BLAIR, 2009).

Esse método foi introduzido na literatura por Paelinck, Caevel e Degueldre (1965) e desenvolvido por Schultz (1976) e Cella (1984). Até a década de 1980, o método de extração hipotética não considerava os efeitos backward linkage e forward linkage, que representava uma limitação ao modelo. Além disso, as avaliações eram subestimadas por não considerar os níveis de ligação total. Cella (1984) propõe uma abordagem utilizando o método de extração hipotética, no qual aqueles efeitos são abarcados (CELLA, 1984, p. 78). Entretanto, de acordo com Song, Liu e Langston (2006), a decomposição dos efeitos por Cella recebeu várias críticas ${ }^{5}$, que se concentraram principalmente nas definições de componentes de ligação para frente e para trás e para a escolha do modelo de quantidade de Leontief e do modelo de preço de Ghosh. 0 método, então, é avançado pelo trabalho de Dietzenbacher, Linden e Steenge (1993).

Dessa forma, o método de extração hipotética utilizado neste trabalho foi proposto por Dietzenbacher, Linden e Steenge (1993) utilizando uma matriz insumoproduto para quantificar as interdependências entre setores e regiões, além de identificar os setores importantes para o desenvolvimento econômico. Os autores apresentam que a vantagem de utilizar o método de insumo-produto é pela sua capacidade de descrever ou detectar as dependências setoriais. A proposta do método de extração hipotética fornece análises complementares às de Hirschman (1958), ou seja, dos índices de ligação para trás e para frente.

Miller e Lahr (2001) aplicaram o método utilizando sete extrações hipotéticas dos modelos Leontief e Ghosh e concluíram que a ligação total derivada do método de extração hipotética é uma medida apropriada para verificar a importância do setor

5 Ver mais sobre em Dietzenbacher, Linden e Steenge (1993). 
extraído. Além disso, os autores sugeriram o uso do modelo Leontief para medir a ligação para trás e o modelo de Ghosh para medir a ligação direta 6 .

Por outro lado, a literatura brasileira que se utiliza do método abordado tem focado sobremaneira na análise regional das interdependências setoriais, utilizando matrizes inter-regionais e interestaduais, além de analisar para o Brasil por meio de matrizes nacionais (HADDAD; PEROBELLI; SANTOS, 2004; 2009; PEROBELLI et al., 2010; PEREIRA; BASTOS; PEROBELLI, 2013). Em estudo mais recente, Cabral, Cabral e Oliveira (2017) aplicaram o método de extração hipotética. As exportações foram extraídas a fim de quantificar a interdependência setorial e o impacto sobre o produto dos setores a partir da lente teórica estruturalista-kaldoriana.

Utilizou-se a matriz de insumo-produto para o Brasil do ano de 2013 disposta com uma agregação de 68 setores e de 128 produtos, disponibilizada pelo Núcleo de Economia Regional e Urbana da USP (NEREUS)7. Cumpre ressaltar que o método apresenta limitações subjacentes, uma vez que se utiliza uma matriz não oficial e por limitações impostas pelo próprio método ao considerar constante uma tecnologia única de produção. Dessa forma, o modelo de insumo-produto apresenta uma série de limitações: 1) coeficiente tecnológico constante (função produção de Leontief), 2) retornos constantes de escala, 3) demanda final definida exogenamente, 4) preços rígidos e oferta perfeitamente elástica ${ }^{8}$.

\subsection{Modelos de Insumo-Produto}

Este trabalho se baseia nos princípios do modelo de insumo-produto de Wassily Leontief (MILLER; BLAIR, 2009), a fim de analisar as relações intersetoriais da economia brasileira.

Em termos matriciais, a forma mais geral da relação insumo-produto é dada por

$$
\mathbf{x}=\mathbf{A x}+\mathbf{f}
$$

em que $\mathbf{x}$ é o vetor de produção setorial; $\mathbf{A}$ é a matriz de coeficientes técnicos de insumo-produto; e f é o vetor de demanda final (MILLER; BLAIR, 2009). Denota-se I uma matriz identidade $n \times n$ e subtrai-se da matriz A, resolvendo, obtém-se

$$
\mathbf{x}=(\mathbf{I}-\mathbf{A})^{-1} \mathbf{f}=\mathbf{B f}
$$

60 modelo será descrito a seguir.

7 A matriz insumo-produto oficial brasileira mais recente apresentada pelo IBGE é para o ano de 2010. Optou-se em utilizar uma matriz mais recente para a economia brasileira.

8 Ver mais nos trabalhos de Domingues, Betarelli Junior e Magalhães (2011); Cabral e Perobelli (2012); Cabral, Cabral e Oliveira (2017). 
onde $(\mathbf{I}-\mathbf{A})^{-1}=\mathbf{B}=\left[b_{i j}\right]$ é conhecido como inversa de Leontief ou matriz de requerimentos totais ${ }^{9}$. Essa matriz $\mathrm{B}$ será essencial para realizar os cálculos dos multiplicadores, índices de ligação e dispersão, além da extração hipotética que será tratada nas próximas subseções.

\subsection{Multiplicadores setoriais}

Os multiplicadores estimam os efeitos de uma mudança exógena sobre o produto, a renda e o emprego de determinado setor da economia e auferir o quanto é gerado direto e indiretamente sobre cada um deles (GUILHOTO, 2011; BATARELLI; PEROBELLI; VALE 2015).

0 multiplicador do produto para o setor $j$ é definido como o valor total da produção em todos os setores da economia que é necessário para satisfazer o valor em reais da demanda final para o produto do setor $j$. Em termos gerais o multiplicador de produção para cada setor é a soma da sua respectiva coluna na matriz inversa de Leontief e pode ser encontrado por

$$
O_{j}=\sum_{i=1}^{n} b_{i j}
$$

onde bij representa os coeficientes da matriz B.

O multiplicador de empregos indica a quantidade de empregos criados, direta e indiretamente, para cada emprego direto criado e de maneira intuitiva o mesmo pode ser encontrado para o multiplicador da renda. Esses resultados podem ser obtidos por meio das equações (4) e (5)

$$
\begin{gathered}
\mathbf{E}=\left[e_{j}\right]=\mathbf{W B}=\left[\sum_{i=1}^{n} w_{i j} b_{i j}\right] \\
\mathbf{R}=\left[r_{j}\right]=\mathbf{L B}=\left[\sum_{i=1}^{n} L_{i j} b_{i j}\right]
\end{gathered}
$$

em que $\mathbf{E}$ e $\mathbf{R}$ são matrizes de multiplicadores sobre o emprego e renda; $\mathbf{W}$ e $\mathbf{L}$ são matrizes diagonais, cujos elementos representam a razão entre o número de trabalhadores empregados e a renda gerada com o valor da produção (x) (BATARELLI JUNIOR; PEROBELLI; VALE, 2015).

Segundo Guilhoto (2011), quando o efeito de multiplicação se restringe somente à demanda de insumos intermediários, estes multiplicadores são chamados de multiplicadores do tipo I. Contudo, ao endogeneizar a demanda das famílias no

9 Para mais detalhes da metodologia completa ver Miller e Blair (2009) e Guilhoto (2011). Ainda, utilizaram-se, nesse trabalho multiplicadores para o modelo fechado de insumo-produto (MILLER; BLAIR, 2009; GUILHOTO, 2011). 
modelo, levando-se em consideração o efeito induzido, estes multiplicadores recebem a denominação de multiplicadores do tipo II ${ }^{10}$.

\section{3 Índices de ligação e estatísticas de variabilidade}

Diversos estudos têm analisado o poder de encadeamento dentro da economia. Seguindo os conceitos de Rasmussen (1956) e Hirschman (1958) (R-H) podem-se calcular os índices de ligação para trás (poder de dispersão) que determina o quanto os setores demandam dos outros e os índices de ligação para frente (sensibilidade da dispersão) mensurando o quanto esse setor é demandado pelos outros (GUILHOTO et al., 1994; TOYOSHIMA; FERREIRA, 2002; BATARELLI JUNIOR; PEROBELLI; VALE, 2015).

Partindo da equação (2) define-se bij como sendo um elemento da matriz inversa de Leontief. Dessa maneira é possível obter os índices de ligação para trás $(U j)$ e os índices de ligação para frente $(U i)$

$$
U_{j}=\frac{\left(\mathbf{B}_{* j} / n\right)}{\mathbf{B}^{*}} \quad U_{i}=\frac{\left(\mathbf{B}_{* i} / n\right)}{\mathbf{B}^{*}} \quad(\forall i, j=1,2, \ldots n)
$$

em que $\mathbf{B}^{*}=\frac{\sum_{i=1}^{n} \sum_{j=1}^{n} b_{i j}}{n^{2}}$ representa a média de todos os coeficientes da matriz inversa de Leontief (B), $\mathbf{B}_{* j}=\sum_{i=1}^{n} b_{i j}$ ), refere-se ao somatório dos coeficientes pela ótica das compras e $\mathbf{B}_{* i}=\sum_{j=1}^{n} b_{i j}$ revela o total dos coeficientes pela ótica das vendas (TOYOSHIMA; FERREIRA, 2002; BATARELLI JUNIOR; PEROBELLI; VALE, 2015).

\subsection{Método de extração hipotética}

Nesse trabalho, seguem-se os procedimentos de Miller e Blair (2009). Primeiramente, modela-se no contexto de insumo-produto excluindo a linha $i$ (forward linkage) e a coluna $j$ (backward linkage) da matriz A. Usando a matriz $\overline{\mathbf{A}}_{(j)}$ para os $(n-1)$ x $(n-1)$ sem o setor $J$ e $\bar{f}_{(j)}$ para o vetor que corresponde à redução da demanda final. 0 produto reduzido da economia é encontrado pela seguinte equação: $\overline{\boldsymbol{x}}_{(j)}=\left[\mathbf{I}-\overline{\mathbf{A}}_{(j)}\right]^{-1} \overline{\boldsymbol{f}}_{(j)}$. A linha e a coluna são substituídas por zeros ao invés de exclui-las. No modelo completo com $n$ setores o produto pode ser encontrado pela equação $\mathbf{x}=(\mathbf{I}-\mathbf{A})^{-1} \mathbf{f}$, de modo que $\boldsymbol{T}_{j}=\mathbf{i}^{\prime} \boldsymbol{x}-\mathbf{i}^{\prime} \boldsymbol{x}_{(j)}$ é uma medida agregada de perda da economia (redução do valor da produção bruta) se o setor $J$ desaparece - tal que, é uma medida da "importância" ou a ligação total do setor $J$. 
Diante desse resultado é feita a normalização na qual pode ser encontrada por meio da divisão pelo produto bruto total (i'x) e multiplicado por 100 e assim produz uma estimativa da redução percentual a atividade $j$ e total da economia.

Para mensurar os índices de ligação para trás (backward linkage) e os índices de ligação para frente (forward linkage), suponha que o setor J compra (backward linkage) insumos de outros setores da economia, dessa forma, ao substituir a coluna $j$ por zeros, os índices de ligação para trás desse setor são removidos e então é possível mensurar o impacto desse fluxo nos outros setores da economia. A metodologia é a mesma supracitada, contudo, somente a coluna é suprimida e a linha do setor permanece.

Por outro lado, para mensurar os fluxos pela ótica das vendas (forward linkage), utiliza-se a matriz B (matriz Gosh) ao invés de se utilizar a matriz A (matriz Leontief). A linha $i$ do setor $J$ é substituída por zeros. É denotada a matriz $\overline{\mathbf{B}}_{(\mathrm{ij})}$ de Gosh com a linha $i$ substituída por zeros. 0 produto antes da extração da linha é encontrado por meio da equação $\mathbf{x}^{\prime}=\mathbf{v}^{\prime}(\mathbf{I}-\mathbf{B})^{-1}$, por outro lado, o produto depois da extração pode ser encontrado por meio da seguinte, $\overline{\mathbf{x}}_{(\mathrm{ij})}^{\prime}=\mathbf{v}^{\prime}\left[\mathbf{I}-\overline{\mathbf{B}}_{(\mathrm{ij})}\right]^{-1}$. 0 índice de ligação para frente pode ser mensurado pela perda agregada do setor, $\mathbf{x}^{\prime} \mathbf{i}-\left[\overline{\mathbf{x}}_{(\mathbf{i j})}^{\prime}\right] \mathbf{i}$, indicando a dependência do setor que vende para os outros setores. 0 índice deve ser normalizado, igual ao índice de ligação para trás, $100 \times\left[x_{i}-x_{(i j)} i\right] / x_{j}$ (MILLER; BLAIR, 2009).

\section{Análise dos setores sucroalcoleiros}

De acordo com os dados da Tabela Insumo-Produto de recursos e usos para o ano de 201311, observa-se que o fluxo de compra e venda do produto cana-de-açúcar manteve inter-relação com os setores e com maior intensidade, respectivamente: setor "fabricação e refino de açúcar" (9) (61,93\% do consumo intermediário), "fabricação de biocombustível" (20) (30,72\%), "fabricação de bebidas" (11) (3,57\%), "alimentação" (48) (2,07\%), "agricultura" (1) (1,37\%), "pecuária, inclusive o apoio à pecuária" (2) (0,33\%) e "produção florestal; pesca e aquicultura" (3) (0,01\%). Analisam-se os dois primeiros setores de manufaturas da cadeia de cana-de-açúcar, uma vez que são os mais significativos e possuem maior valor agregado.

Na Tabela 3, são apresentados os principais resultados dos multiplicadores de cada setor obtidos por meio da matriz insumo-produto do Brasil de 2013 e classificados pelas exportações setoriais de maior dinamismo. Observa-se que os setores de análise "fabricação e refino de açúcar" (9) e "fabricação de biocombustível" (20) apresentam valores acima da média para todos os

11 Disponibilizada pelo NEREUS da USP. 
multiplicadores. Os resultados dos multiplicadores de produção setoriais revelam a variação no volume de produção da ordem de 2,34 e 2,31, respectivamente, induzidos pelo aumento de $\mathrm{R} \$ 1,00$ na demanda final de cada setor. A média do multiplicador da produção é de 1,80. Destacam-se os multiplicadores (tipo II - que levam em consideração a demanda das famílias) da renda de 3,20 e 3,61 e do emprego de 6,65 e 9,11, sendo a média nacional da renda 2,95 e do emprego 6,40. Os dois setores, produção e processamento, produzem impactos significativos sobre toda a economia levando em consideração as mudanças ocorridas na demanda final. Vale ainda observar que esses setores apresentam baixo dinamismo na pauta exportadora somando apenas $4,06 \%$ das exportações totais brasileiras (Tabela 3 e Anexo 2).

Comparativamente, aos resultados encontrados, para os setores objeto de análise desse trabalho, por Batarelli Junior, Perobelli e Vale (2015), os quais utilizaram uma matriz insumo-produto brasileira para o ano de 2011, apresentaram resultados similares e também valores acima da média para todos os setores da economia. Nesse sentido, os autores encontraram multiplicadores de produção setoriais para o setor de "fabricação e refino de açúcar" $(2,24)$ e "fabricação de biocombustível" $(2,35)$, sendo que esse último apresentava valor superior ao encontrado para o ano de 2013. Os multiplicadores da renda (tipo I) apresentaram respectivamente 2,28 e 2,7912. Ainda, os resultados dos multiplicadores do emprego (tipo I), em 2011, foram da ordem de 5,79 para "fabricação e refino de açúcar" e da ordem de 7,77 para "fabricação de biocombustível" (valores maiores aos encontrados para 2013). No que tange as exportações, em 2011 a soma da participação dos dois setores no total das exportações brasileiras foi 4,82\% ${ }^{13}$. Esses resultados apontam para uma queda no dinamismo das exportações da cadeia da cana entre os anos de 2011 e 2013, principalmente pela queda do setor de "fabricação e refino de açúcar".

12 Em 2011, o multiplicador da renda para o setor "fabricação e refino de açúcar" era menor do que em 2013. Por outro lado, o setor "fabricação de biocombustível" apresentou resultado superior para esse indicador em 2013.

13 A participação dos setores no total das exportações brasileiras apresenta: "fabricação e refino de açúcar" $(4,21 \%)$ e fabricação de biocombustível $(0,61 \%)$. 


\section{Tabela 3: Multiplicadores Setoriais de Maior Participação na Pauta Exportadora Brasileira (2013)}

\begin{tabular}{|c|c|c|c|c|c|c|}
\hline $\begin{array}{l}\text { Cod. } \\
\text { Setor }\end{array}$ & $\begin{array}{l}\text { Multiplicador de } \\
\text { Produção }\end{array}$ & $\begin{array}{c}\text { Multiplicador de } \\
\text { Renda (Tipo I) }\end{array}$ & $\begin{array}{l}\text { Multiplicador de } \\
\text { Renda (Tipo II) }\end{array}$ & $\begin{array}{l}\text { Multiplicador de } \\
\text { Emprego (Tipo I) }\end{array}$ & $\begin{array}{l}\text { Multiplicador de } \\
\text { Emprego (Tipo II) }\end{array}$ & \% Exportações \\
\hline 1 & 1,63 & 1,98 & 2,75 & 1,19 & 1,34 & $11,10 \%$ \\
\hline 6 & 1,46 & 2,18 & 3,03 & 5,90 & 10,29 & $10,08 \%$ \\
\hline 42 & 1,53 & 1,37 & 1,91 & 1,25 & 1,64 & $9,26 \%$ \\
\hline 8 & 2,46 & 3,86 & 5,37 & 10,44 & 12,45 & $4,92 \%$ \\
\hline 5 & 1,44 & 2,04 & 2,84 & 10,07 & 19,23 & $4,57 \%$ \\
\hline 35 & 1,92 & 1,94 & 2,70 & 3,21 & 5,53 & $4,31 \%$ \\
\hline 10 & 2,27 & 2,98 & 4,14 & 3,71 & 4,76 & $4,02 \%$ \\
\hline 27 & 2,11 & 2,77 & 3,86 & 6,31 & 10,30 & $3,26 \%$ \\
\hline 9 & 2,34 & 2,30 & 3,20 & 5,17 & 6,65 & $3,18 \%$ \\
\hline 33 & 2,18 & 3,58 & 4,98 & 9,39 & 15,21 & $3,08 \%$ \\
\hline 19 & 2,46 & 10,78 & 14,99 & 72,28 & 115,17 & $3,04 \%$ \\
\hline 32 & 1,97 & 2,00 & 2,79 & 3,09 & 5,04 & $2,53 \%$ \\
\hline 56 & 1,48 & 1,39 & 1,93 & 1,51 & 2,39 & $2,46 \%$ \\
\hline 21 & 2,10 & 3,42 & 4,76 & 8,84 & 14,28 & $2,27 \%$ \\
\hline 28 & 2,23 & 2,91 & 4,05 & 4,66 & 7,31 & $2,25 \%$ \\
\hline 17 & 2,09 & 2,46 & 3,42 & 4,11 & 6,14 & $2,23 \%$ \\
\hline 34 & 2,06 & 1,93 & 2,68 & 2,97 & 4,96 & $1,98 \%$ \\
\hline 43 & 1,97 & 1,68 & 2,34 & 1,48 & 2,03 & $1,64 \%$ \\
\hline 53 & 1,54 & 1,57 & 2,18 & 2,89 & 5,75 & $1,61 \%$ \\
\hline 55 & 1,44 & 1,39 & 1,93 & 1,42 & 2,12 & $1,45 \%$ \\
\hline 41 & 1,56 & 1,43 & 1,99 & 1,22 & 1,58 & $1,19 \%$ \\
\hline 59 & 1,43 & 1,21 & 1,69 & 1,18 & 1,63 & $1,09 \%$ \\
\hline 31 & 2,06 & 2,11 & 2,94 & 3,04 & 4,93 & $1,07 \%$ \\
\hline 46 & 1,57 & 1,42 & 1,98 & 1,67 & 2,72 & $1,06 \%$ \\
\hline 12 & 2,00 & 3,21 & 4,47 & 11,82 & 15,65 & $1,03 \%$ \\
\hline 15 & 1,99 & 1,78 & 2,48 & 1,78 & 2,35 & $1,00 \%$ \\
\hline 25 & 2,05 & 1,96 & 2,72 & 2,45 & 3,75 & $0,99 \%$ \\
\hline 20 & 2,31 & 2,60 & 3,61 & 7,12 & 9,11 & $0,88 \%$ \\
\hline 47 & 1,62 & 1,33 & 1,85 & 1,33 & 1,80 & $0,76 \%$ \\
\hline 29 & 1,98 & 1,78 & 2,47 & 1,80 & 2,69 & $0,75 \%$ \\
\hline 45 & 1,68 & 1,79 & 2,49 & 3,94 & 7,12 & $0,74 \%$ \\
\hline 7 & 2,24 & 2,44 & 3,39 & 4,10 & 6,60 & $0,73 \%$ \\
\hline 22 & 2,04 & 2,52 & 3,50 & 5,39 & 8,81 & $0,73 \%$ \\
\hline 2 & 1,77 & 1,69 & 2,36 & 1,16 & 1,26 & $0,73 \%$ \\
\hline 26 & 2,02 & 1,96 & 2,72 & 1,99 & 2,88 & $0,64 \%$ \\
\hline 48 & 1,79 & 1,67 & 2,32 & 1,34 & 1,60 & $0,56 \%$ \\
\hline 16 & 1,89 & 1,72 & 2,40 & 1,74 & 2,18 & $0,55 \%$ \\
\hline 54 & 1,11 & 3,16 & 4,39 & 1,91 & 2,70 & $0,52 \%$ \\
\hline 30 & 1,81 & 2,47 & 3,43 & 4,26 & 6,71 & $0,50 \%$ \\
\hline Média & 1,80 & 2,12 & 2,95 & 4,15 & 6,40 & - \\
\hline
\end{tabular}

Nota: 1) A média simples dos multiplicadores é calculada para os 68 setores da economia e que se encontra também no Anexo 2; 2) A descrição e códigos dos setores estão relacionados na Tabela 4 e no Anexo 1.

Fonte: Adaptado de Batarelli Junior, Perobelli e Vale (2015) e atualizado para o ano de 2013. 
0 Gráfico 5 revela os índices de encadeamento das atividades da economia brasileira para o ano de 2013. A partir dos índices de ligação R-H observa-se quais setores aumentam acima da média dado uma mudança unitária na de manda final de todos os setores, além de revelar o grau de dependência de um determinado setor diante dos outros setores da economia. No quadrante I observam-se os setores-chave da economia, setores estes que contribuem acima da média para a economia, o quadrante II apresenta os setores que possuem forte encadeamento para frente, o quadrante III, fraco encadeamento para trás e para frente, e o quadrante IV, forte encadeamento para trás.

Os setores "fabricação e refino de açúcar" (9) e "fabricação de biocombustível" (20) são classificados como forte encadeamento para trás (Quadrante IV - Gráfico 1), pode-se indicar a importância da aquisição de insumo por parte desses setores dentro do próprio estado (BATARELLI JUNIOR; PEROBELLI; VALE, 2015). Dessa forma, observa-se que são setores de maior dependência a nível regional na aquisição de insumos, como é no caso do Estado de São Paulo que é o maior produtor a nível nacional (BACCHI; CALDARELLI, 2015). Esses setores ainda apresentam alto poder de dispersão para frente e baixo poder de dispersão para trás (Anexo 1).

Gráfico 5: Índices de Encadeamentos (2013)

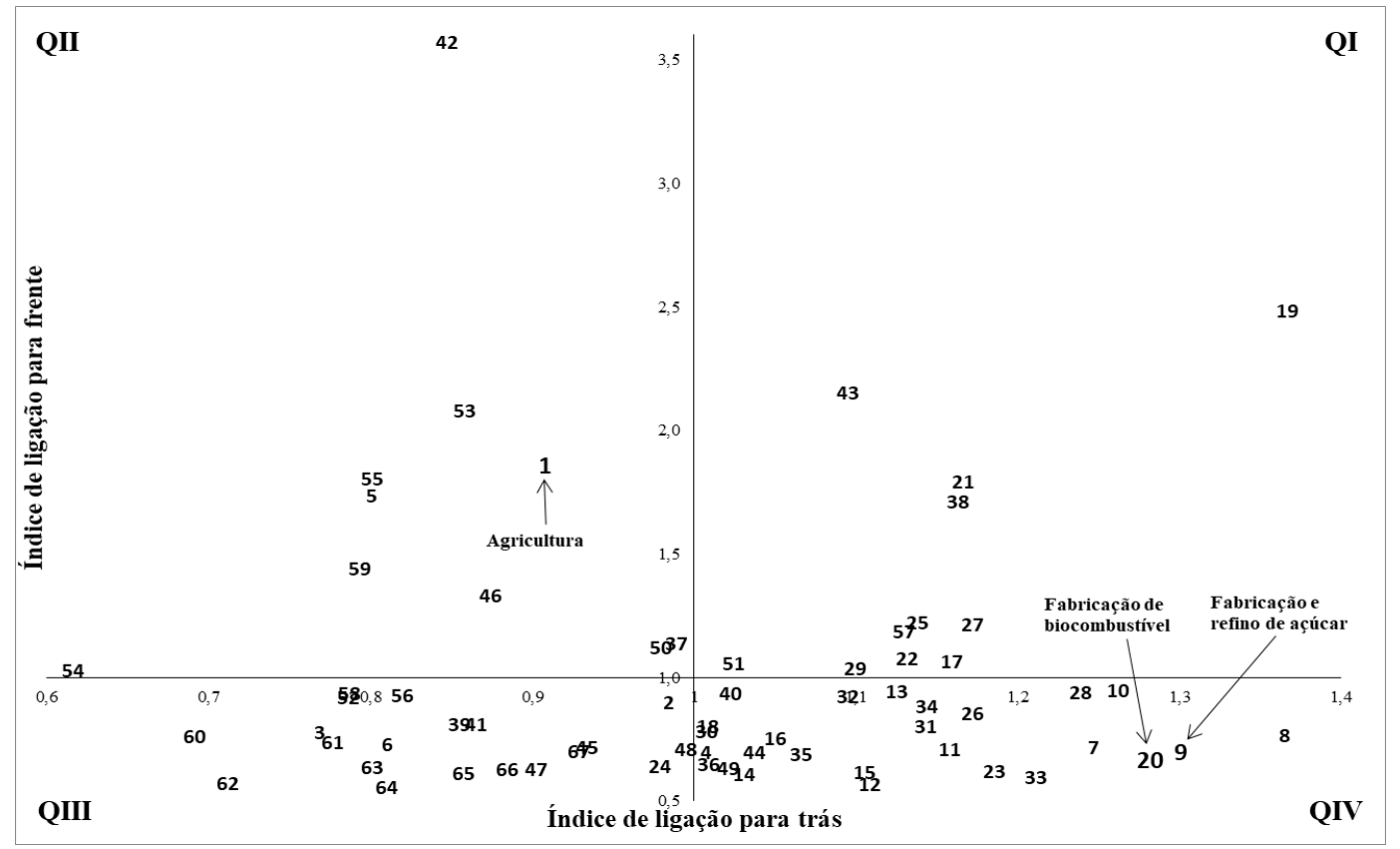

Nota: Os códigos dos setores estão relacionados e com seus respectivos nomes na Tabela 4. Fonte: Adaptado de Batarelli Junior, Perobelli e Vale (2015) e atualizado para o ano de 2013. 
A Tabela 4 apresenta os resultados do método de extração hipotética a fim de investigar a importância do setor sucroalcooleiro para a economia brasileira e quantificar os índices de ligação por meio da estrutura de insumo-produto. Observa-se que o setor de "fabricação e refino de açúcar" (9) tem forte ligação para trás, corroborando os resultados trazidos pelo Gráfico 5. Quando é extraído o fluxo de compras (colunaj) desse setor, revelase o impacto nos outros setores da economia. 0 setor que sofreu com maior intensidade é o de "agricultura, inclusive o apoio à agricultura e a pós-colheita" (1) em que se observa uma redução de $10,53 \%$ do produto. Esse setor fornece o principal insumo para a fabricação do açúcar e etanol (cana-de-açúcar), o que resulta num grande impacto recebido. Além da redução do produto total da economia de 0,75\%, outros setores que sofrem maior redução estão ligados direta ou indiretamente são os de "fabricação de químicos orgânicos e inorgânicos, resinas e elastômeros" (21) (-3,17\%), "fabricação e refino de açúcar" (9) (-3,08\%), "fabricação de defensivos, desinfestantes, tintas e químicos diversos" (22) (-2,64\%), "armazenamento, atividades auxiliares dos transportes e correio" (46) (-2,49\%), "transporte terrestre" (43) (-1,59\%), "fabricação de biocombustíveis" (20) $(-1,44 \%)$.

Como era o esperado, os resultados de dependência setorial para frente não foram expressivos e obtiveram as maiores taxas de redução os setores de "fabricação e refino de açúcar" (-3,08\%), "refino de petróleo e coquerias" (19) (-2,73\%), "outros produtos alimentares" (10) (-2,29\%), "fabricação de biocombustíveis" (20) (-2,09\%), "fabricação de bebidas" (11) (-1,67\%). 0 produto total da economia cairia em $0,36 \%$.

Por outro lado, a extração hipotética do setor de fabricação e refino de açúcar revela um impacto direto no setor com uma redução de $33,27 \%$ e uma queda do produto total da economia de $0,93 \%$, caso esse setor desaparecesse. Contudo, quando se compara a extração hipotética do setor de grande importância para a economia brasileira, "agricultura, inclusive o apoio à agricultura e a pós-colheita" (1), cujo resultado é uma redução de $3,20 \%$ do produto total da economia, observa-se que aquele setor pode apresentar preocupações em tempos de crise e vulnerabilidade econômica.

Os resultados para o setor de "fabricação de biocombustível" (20) são menos expressivos do que o setor de fabricação e refino de açúcar. 0 maior grau de dependência para trás é com o setor de "agricultura, inclusive o apoio à agricultura e a pós-colheita" (1) $(-5,90 \%)$, seguido pelos setores de "fabricação de químicos orgânicos e inorgânicos, resinas e elastômeros (21) (-2,10\%), "fabricação de defensivos, desinfestantes, tintas e químicos diversos" (22) (-1,67\%), "fabricação e refino de açúcar" (9) (-1,31\%), "extração de carvão mineral e de minerais não-metálicos" (4) (-1,14\%) e "manutenção, reparação e instalação de máquinas e equipamentos" (-1,08\%). A queda do produto total da economia revela-se $0,60 \%$ caso o mesmo desaparecesse. Observa-se uma grande concentração de setores não ligados diretamente à produção de biocombustível. Os encadeamentos para frente desse setor são ainda menos expressivos, os quais destacam-se os concêntricos ao setor em análise e ao de serviços como os de "refino de petróleo e coquerias" (19) ($3,75 \%$ ), "fabricação de produtos de limpeza, cosméticos/perfumaria e higiene pessoal" (23) (-2,04\%), "fabricação de biocombustíveis" (20) (-1,04\%), "transporte terrestre" (43) $(-0,91 \%)$, "fabricação e refino de açúcar" (9) (-0,90\%). 
Tabela 4: Índices de ligação, impactos sobre o produto setorial e total da economia (\%) advindos da extração hipotética dos setores: fabricação de açúcar, fabricação de biocombustivel e agricultura (2013)

\begin{tabular}{|c|c|c|c|c|c|c|c|c|c|c|}
\hline \multirow{2}{*}{$\begin{array}{l}\text { Cod. } \\
\text { Setor }\end{array}$} & \multirow{2}{*}{ Setores } & \multicolumn{3}{|c|}{ Ligação para trás } & \multicolumn{3}{|c|}{ Ligação para frente } & \multicolumn{3}{|c|}{ Extração Setorial } \\
\hline & & S9 & S20 & S1 & S9 & S20 & S1 & S9 & S20 & S1 \\
\hline 1 & Agricultura, inclusive o apoio à agricultura e a pós-colheita & $-10,53 \%$ & $-5,90 \%$ & $-2,93 \%$ & $-0,25 \%$ & $-0,27 \%$ & $-2,93 \%$ & $-10,53 \%$ & $-5,90 \%$ & $-51,05 \%$ \\
\hline 2 & Pecuária, inclusive o apoio à pecuária & $-0,22 \%$ & $-0,32 \%$ & $-0,77 \%$ & $-0,42 \%$ & $-0,30 \%$ & $-6,08 \%$ & $-0,22 \%$ & $-0,32 \%$ & $-0,77 \%$ \\
\hline 3 & Produção florestal; pesca e aquicultura & $-0,47 \%$ & $-0,31 \%$ & $-3,93 \%$ & $-0,15 \%$ & $-0,14 \%$ & $-1,38 \%$ & $-0,47 \%$ & $-0,31 \%$ & $-3,93 \%$ \\
\hline 4 & Extração de carvão mineral e de minerais não-metálicos & $-0,78 \%$ & $-1,14 \%$ & $-5,57 \%$ & $-0,32 \%$ & $-0,31 \%$ & $-0,69 \%$ & $-0,78 \%$ & $-1,14 \%$ & $-5,57 \%$ \\
\hline $\mathbf{5}$ & Extração de petróleo e gás, inclusive as atividades de apoio & $-1,00 \%$ & $-0,59 \%$ & $-4,32 \%$ & $-0,13 \%$ & $-0,16 \%$ & $-0,20 \%$ & $-1,00 \%$ & $-0,59 \%$ & $-4,32 \%$ \\
\hline 6 & Extração de minério de ferro, inclusive beneficiamentos e a aglomeração & $-0,03 \%$ & $-0,02 \%$ & $-0,12 \%$ & $-0,13 \%$ & $-0,16 \%$ & $-0,21 \%$ & $-0,03 \%$ & $-0,02 \%$ & $-0,12 \%$ \\
\hline 7 & Extração de minerais metálicos não-ferrosos, inclusive beneficiamentos & $-0,14 \%$ & $-0,09 \%$ & $-0,61 \%$ & $-0,40 \%$ & $-0,48 \%$ & $-0,66 \%$ & $-0,14 \%$ & $-0,09 \%$ & $-0,61 \%$ \\
\hline 8 & Abate e produtos de carne, inclusive os produtos do laticínio e da pesca & $-0,02 \%$ & $-0,26 \%$ & $-0,09 \%$ & $-0,59 \%$ & $-0,34 \%$ & $-7,57 \%$ & $-0,02 \%$ & $-0,26 \%$ & $-0,09 \%$ \\
\hline 9 & Fabricação e refino de açúcar & $-3,08 \%$ & $-1,31 \%$ & $-1,26 \%$ & $-3,08 \%$ & $-0,90 \%$ & $-53,04 \%$ & $-33,27 \%$ & $-1,31 \%$ & $-1,26 \%$ \\
\hline 10 & Outros produtos alimentares & $-0,14 \%$ & $-0,69 \%$ & $-1,01 \%$ & $-2,29 \%$ & $-0,68 \%$ & $-26,60 \%$ & $-0,14 \%$ & $-0,69 \%$ & $-1,01 \%$ \\
\hline 11 & Fabricação de bebidas & $-0,03 \%$ & $-0,02 \%$ & $-0,09 \%$ & $-1,67 \%$ & $-0,47 \%$ & $-5,19 \%$ & $-0,03 \%$ & $-0,02 \%$ & $-0,09 \%$ \\
\hline 12 & Fabricação de produtos do fumo & $0,00 \%$ & $0,00 \%$ & $-0,01 \%$ & $-0,12 \%$ & $-0,13 \%$ & $-26,73 \%$ & $0,00 \%$ & $0,00 \%$ & $-0,01 \%$ \\
\hline 13 & Fabricação de produtos têxteis & $-0,38 \%$ & $-0,10 \%$ & $-1,26 \%$ & $-0,15 \%$ & $-0,17 \%$ & $-11,02 \%$ & $-0,38 \%$ & $-0,10 \%$ & $-1,26 \%$ \\
\hline 14 & Confecção de artefatos do vestuário e acessórios & $-0,03 \%$ & $-0,02 \%$ & $-0,10 \%$ & $-0,08 \%$ & $-0,09 \%$ & $-3,50 \%$ & $-0,03 \%$ & $-0,02 \%$ & $-0,10 \%$ \\
\hline 15 & Fabricação de calçados e de artefatos de couro & $-0,01 \%$ & $-0,02 \%$ & $-0,05 \%$ & $-0,14 \%$ & $-0,14 \%$ & $-1,68 \%$ & $-0,01 \%$ & $-0,02 \%$ & $-0,05 \%$ \\
\hline 16 & Fabricação de produtos da madeira & $-0,28 \%$ & $-0,18 \%$ & $-2,05 \%$ & $-0,13 \%$ & $-0,14 \%$ & $-1,06 \%$ & $-0,28 \%$ & $-0,18 \%$ & $-2,05 \%$ \\
\hline 17 & Fabricação de celulose, papel e produtos de papel & $-0,29 \%$ & $-0,24 \%$ & $-1,24 \%$ & $-0,19 \%$ & $-0,21 \%$ & $-0,96 \%$ & $-0,29 \%$ & $-0,24 \%$ & $-1,24 \%$ \\
\hline 18 & Impressão e reprodução de gravações & $-0,46 \%$ & $-0,29 \%$ & $-1,28 \%$ & $-0,12 \%$ & $-0,11 \%$ & $-0,36 \%$ & $-0,46 \%$ & $-0,29 \%$ & $-1,28 \%$ \\
\hline 19 & Refino de petróleo e coquerias & $-1,43 \%$ & $-0,83 \%$ & $-5,84 \%$ & $-2,73 \%$ & $-3,75 \%$ & $-3,41 \%$ & $-1,43 \%$ & $-0,83 \%$ & $-5,84 \%$ \\
\hline 20 & Fabricação de biocombustíveis & $-1,44 \%$ & $-1,04 \%$ & $-2,18 \%$ & $-2,09 \%$ & $-1,04 \%$ & $-47,58 \%$ & $-1,44 \%$ & $-42,05 \%$ & $-2,18 \%$ \\
\hline 21 & Fabricação de químicos orgânicos e inorgânicos, resinas e elastômeros & $-3,17 \%$ & $-2,10 \%$ & $-27,12 \%$ & $-0,51 \%$ & $-0,66 \%$ & $-0,82 \%$ & $-3,17 \%$ & $-2,10 \%$ & $-27,12 \%$ \\
\hline 22 & Fabricação de defensivos, desinfestantes, tintas e químicos diversos & $-2,64 \%$ & $-1,67 \%$ & $-23,60 \%$ & $-1,10 \%$ & $-0,63 \%$ & $-1,33 \%$ & $-2,64 \%$ & $-1,67 \%$ & $-23,60 \%$ \\
\hline 23 & Fabricação de produtos de limpeza, cosméticos/perfumaria e higiene pessoal & $-0,24 \%$ & $-0,15 \%$ & $-1,56 \%$ & $-1,55 \%$ & $-2,04 \%$ & $-2,76 \%$ & $-0,24 \%$ & $-0,15 \%$ & $-1,56 \%$ \\
\hline 24 & Fabricação de produtos farmoquímicos e farmacêuticos & $-0,12 \%$ & $-0,08 \%$ & $-0,96 \%$ & $-0,67 \%$ & $-0,88 \%$ & $-1,02 \%$ & $-0,12 \%$ & $-0,08 \%$ & $-0,96 \%$ \\
\hline 25 & Fabricação de produtos de borracha e de material plástico & $-0,50 \%$ & $-0,27 \%$ & $-1,68 \%$ & $-0,21 \%$ & $-0,24 \%$ & $-0,63 \%$ & $-0,50 \%$ & $-0,27 \%$ & $-1,68 \%$ \\
\hline 26 & Fabricação de produtos de minerais não-metálicos & $-0,51 \%$ & $-0,24 \%$ & $-3,19 \%$ & $-0,22 \%$ & $-0,27 \%$ & $-0,50 \%$ & $-0,51 \%$ & $-0,24 \%$ & $-3,19 \%$ \\
\hline 27 & Produção de ferro-gusa/ferroligas, siderurgia e tubos de aço sem costura & $-0,17 \%$ & $-0,11 \%$ & $-0,65 \%$ & $-0,19 \%$ & $-0,21 \%$ & $-0,41 \%$ & $-0,17 \%$ & $-0,11 \%$ & $-0,65 \%$ \\
\hline 28 & Metalurgia de metais não-ferosos e a fundição de metais & $-0,20 \%$ & $-0,13 \%$ & $-0,85 \%$ & $-0,21 \%$ & $-0,25 \%$ & $-0,49 \%$ & $-0,20 \%$ & $-0,13 \%$ & $-0,85 \%$ \\
\hline 29 & Fabricação de produtos de metal, exceto máquinas e equipamentos & $-0,27 \%$ & $-0,18 \%$ & $-0,96 \%$ & $-0,14 \%$ & $-0,16 \%$ & $-0,36 \%$ & $-0,27 \%$ & $-0,18 \%$ & $-0,96 \%$ \\
\hline 30 & Fabricação de equipamentos de informática, produtos eletrônicos e ópticos & $-0,07 \%$ & $-0,04 \%$ & $-0,16 \%$ & $-0,07 \%$ & $-0,08 \%$ & $-0,31 \%$ & $-0,07 \%$ & $-0,04 \%$ & $-0,16 \%$ \\
\hline 31 & Fabricação de máquinas e equipamentos elétricos & $-0,18 \%$ & $-0,11 \%$ & $-0,55 \%$ & $-0,14 \%$ & $-0,16 \%$ & $-0,38 \%$ & $-0,18 \%$ & $-0,11 \%$ & $-0,55 \%$ \\
\hline 32 & Fabricação de máquinas e equipamentos mecânicos & $-0,12 \%$ & $-0,09 \%$ & $-0,27 \%$ & $-0,17 \%$ & $-0,12 \%$ & $-0,38 \%$ & $-0,12 \%$ & $-0,09 \%$ & $-0,27 \%$ \\
\hline 33 & Fabricação de automóveis, caminhões e ônibus, exceto peças & $-0,04 \%$ & $-0,01 \%$ & $-0,03 \%$ & $-0,12 \%$ & $-0,13 \%$ & $-0,32 \%$ & $-0,04 \%$ & $-0,01 \%$ & $-0,03 \%$ \\
\hline 34 & Fabricação de peças e acessórios para veículos automotores & $-0,20 \%$ & $-0,10 \%$ & $-0,41 \%$ & $-0,11 \%$ & $-0,13 \%$ & $-0,47 \%$ & $-0,20 \%$ & $-0,10 \%$ & $-0,41 \%$ \\
\hline 35 & Fabricação de outros equipamentos de transporte, exceto veículos automotores & $-0,08 \%$ & $-0,05 \%$ & $-0,14 \%$ & $-0,10 \%$ & $-0,10 \%$ & $-0,30 \%$ & $-0,08 \%$ & $-0,05 \%$ & $-0,14 \%$ \\
\hline 36 & Fabricação de móveis e de produtos de indústrias diversas & $-0,05 \%$ & $-0,03 \%$ & $-0,16 \%$ & $-0,10 \%$ & $-0,11 \%$ & $-0,59 \%$ & $-0,05 \%$ & $-0,03 \%$ & $-0,16 \%$ \\
\hline 37 & Manutenção, reparação e instalação de máquinas e equipamentos & $-1,39 \%$ & $-1,08 \%$ & $-1,86 \%$ & $-0,16 \%$ & $-0,10 \%$ & $-0,32 \%$ & $-1,39 \%$ & $-1,08 \%$ & $-1,86 \%$ \\
\hline 38 & Energia elétrica, gás natural e outras utilidades & $-0,61 \%$ & $-0,42 \%$ & $-4,39 \%$ & $-0,16 \%$ & $-0,20 \%$ & $-0,28 \%$ & $-0,61 \%$ & $-0,42 \%$ & $-4,39 \%$ \\
\hline 39 & Água, esgoto e gestão de resíduos & $-0,31 \%$ & $-0,16 \%$ & $-0,85 \%$ & $-0,09 \%$ & $-0,10 \%$ & $-0,23 \%$ & $-0,31 \%$ & $-0,16 \%$ & $-0,85 \%$ \\
\hline 40 & Construção & $-0,03 \%$ & $-0,02 \%$ & $-0,07 \%$ & $-0,15 \%$ & $-0,17 \%$ & $-0,40 \%$ & $-0,03 \%$ & $-0,02 \%$ & $-0,07 \%$ \\
\hline 41 & Comércio e repar & $-0,16 \%$ & $-0,08 \%$ & $-0,45 \%$ & $-0,10 \%$ & $-0,11 \%$ & $-0,21 \%$ & $-0,16 \%$ & $-0,08 \%$ & $-0,45 \%$ \\
\hline 42 & Comércio por atacado e a varejo, exceto veículos automotores & $-0,44 \%$ & $-0,35 \%$ & $-2,13 \%$ & $-0,12 \%$ & $-0,13 \%$ & $-1,50 \%$ & $-0,44 \%$ & $-0,35 \%$ & $-2,13 \%$ \\
\hline 43 & Transporte terrestre & $-1,59 \%$ & $-0,83 \%$ & $-3,12 \%$ & $-0,67 \%$ & $-0,91 \%$ & $-0,92 \%$ & $-1,59 \%$ & $-0,83 \%$ & $-3,12 \%$ \\
\hline 44 & Transporte aquaviário & $-1,33 \%$ & $-0,53 \%$ & $-2,89 \%$ & $-0,24 \%$ & $-0,31 \%$ & $-0,37 \%$ & $-1,33 \%$ & $-0,53 \%$ & $-2,89 \%$ \\
\hline 45 & Transporte aéreo & $-0,29 \%$ & $-0,17 \%$ & $-0,96 \%$ & $-0,25 \%$ & $-0,32 \%$ & $-0,48 \%$ & $-0,29 \%$ & $-0,17 \%$ & $-0,96 \%$ \\
\hline 46 & Armazenamento, atividades auxiliares dos transportes e correio & $-2,49 \%$ & $-0,84 \%$ & $-2,13 \%$ & $-0,11 \%$ & $-0,14 \%$ & $-0,21 \%$ & $-2,49 \%$ & $-0,84 \%$ & $-2,13 \%$ \\
\hline 47 & Alojamento & $-0,26 \%$ & $-0,14 \%$ & $-0,64 \%$ & $-0,13 \%$ & $-0,08 \%$ & $-1,76 \%$ & $-0,26 \%$ & $-0,14 \%$ & $-0,64 \%$ \\
\hline 48 & Alimentação & $-0,03 \%$ & $-0,02 \%$ & $-0,10 \%$ & $-0,76 \%$ & $-0,26 \%$ & $-4,37 \%$ & $-0,03 \%$ & $-0,02 \%$ & $-0,10 \%$ \\
\hline 49 & Edição e edição integrada à impressão & $-0,17 \%$ & $-0,10 \%$ & $-0,54 \%$ & $-0,08 \%$ & $-0,08 \%$ & $-0,32 \%$ & $-0,17 \%$ & $-0,10 \%$ & $-0,54 \%$ \\
\hline 50 & Atividades de televisão, rádio, cinema e gravação/edição de som & $-0,47 \%$ & $-0,28 \%$ & $-1,11 \%$ & $-0,06 \%$ & $-0,05 \%$ & $-0,21 \%$ & $-0,47 \%$ & $-0,28 \%$ & $-1,11 \%$ \\
\hline 51 & Telecomunicações & $-0,28 \%$ & $-0,16 \%$ & $-0,48 \%$ & $-0,05 \%$ & $-0,04 \%$ & $-0,21 \%$ & $-0,28 \%$ & $-0,16 \%$ & $-0,48 \%$ \\
\hline 52 & Desenvolvimento de sistemas e outros serviços de informação & $-0,23 \%$ & $-0,13 \%$ & $-0,70 \%$ & $-0,03 \%$ & $-0,03 \%$ & $-0,10 \%$ & $-0,23 \%$ & $-0,13 \%$ & $-0,70 \%$ \\
\hline 53 & Intermediação financeira, seguros e previdência complementar & $-0,65 \%$ & $-0,37 \%$ & $-1,83 \%$ & $-0,04 \%$ & $-0,03 \%$ & $-0,13 \%$ & $-0,65 \%$ & $-0,37 \%$ & $-1,83 \%$ \\
\hline 54 & Atividades imobiliárias & $-0,09 \%$ & $-0,06 \%$ & $-0,20 \%$ & $-0,01 \%$ & $-0,01 \%$ & $-0,03 \%$ & $-0,09 \%$ & $-0,06 \%$ & $-0,20 \%$ \\
\hline 55 & Atividades jurídicas, contábeis, consultoria e sedes de empresas & $-0,99 \%$ & $-0,61 \%$ & $-2,10 \%$ & $-0,04 \%$ & $-0,04 \%$ & $-0,14 \%$ & $-0,99 \%$ & $-0,61 \%$ & $-2,10 \%$ \\
\hline 56 & Serviços de arquitetura, engenharia, testes/análises técnicas e P \& D & $-0,96 \%$ & $-0,54 \%$ & $-1,96 \%$ & $-0,10 \%$ & $-0,12 \%$ & $-0,23 \%$ & $-0,96 \%$ & $-0,54 \%$ & $-1,96 \%$ \\
\hline 57 & Outras atividades profissionais, científicas e técnicas & $-0,52 \%$ & $-0,31 \%$ & $-1,27 \%$ & $-0,06 \%$ & $-0,06 \%$ & $-0,23 \%$ & $-0,52 \%$ & $-0,31 \%$ & $-1,27 \%$ \\
\hline 58 & Aluguéis não-imobiliários e gestão de ativos de propriedade intelectual & $-1,03 \%$ & $-0,41 \%$ & $-1,85 \%$ & $-0,07 \%$ & $-0,08 \%$ & $-0,15 \%$ & $-1,03 \%$ & $-0,41 \%$ & $-1,85 \%$ \\
\hline 59 & Outras atividades administrativas e serviços complementares & $-0,51 \%$ & $-0,32 \%$ & $-0,93 \%$ & $-0,06 \%$ & $-0,05 \%$ & $-0,22 \%$ & $-0,51 \%$ & $-0,32 \%$ & $-0,93 \%$ \\
\hline 60 & Atividades de vigilância, segurança e investigação & $-0,84 \%$ & $-0,27 \%$ & $-1,33 \%$ & $-0,12 \%$ & $-0,16 \%$ & $-0,19 \%$ & $-0,84 \%$ & $-0,27 \%$ & $-1,33 \%$ \\
\hline 61 & Administração pública, defesa e seguridade social & $-0,04 \%$ & $-0,02 \%$ & $-0,09 \%$ & $-0,09 \%$ & $-0,09 \%$ & $-0,42 \%$ & $-0,04 \%$ & $-0,02 \%$ & $-0,09 \%$ \\
\hline 62 & Educação pública & $-0,01 \%$ & $0,00 \%$ & $-0,01 \%$ & $-0,08 \%$ & $-0,06 \%$ & $-0,44 \%$ & $-0,01 \%$ & $0,00 \%$ & $-0,01 \%$ \\
\hline 63 & Educação privada & $-0,08 \%$ & $-0,05 \%$ & $-0,19 \%$ & $-0,06 \%$ & $-0,05 \%$ & $-0,22 \%$ & $-0,08 \%$ & $-0,05 \%$ & $-0,19 \%$ \\
\hline 64 & Saúde pública & $0,00 \%$ & $0,00 \%$ & $0,00 \%$ & $-0,11 \%$ & $-0,08 \%$ & $-0,56 \%$ & $0,00 \%$ & $0,00 \%$ & $0,00 \%$ \\
\hline 65 & Saúde privada & $0,00 \%$ & $0,00 \%$ & $0,00 \%$ & $-0,09 \%$ & $-0,08 \%$ & $-0,48 \%$ & $0,00 \%$ & $0,00 \%$ & $0,00 \%$ \\
\hline 66 & Atividades artísticas, criativas e de espetáculos & $-0,07 \%$ & $-0,04 \%$ & $-0,17 \%$ & $-0,09 \%$ & $-0,06 \%$ & $-0,21 \%$ & $-0,07 \%$ & $-0,04 \%$ & $-0,17 \%$ \\
\hline 67 & Organizações associativas e outros serviços pessoais & $-0,13 \%$ & $-0,07 \%$ & $-0,27 \%$ & $-0,16 \%$ & $-0,14 \%$ & $-0,79 \%$ & $-0,13 \%$ & $-0,07 \%$ & $-0,27 \%$ \\
\hline 68 & Serviços domésticos & $0,00 \%$ & $0,00 \%$ & $0,00 \%$ & $0,00 \%$ & $0,00 \%$ & $0,00 \%$ & $0,00 \%$ & $0,00 \%$ & $0,00 \%$ \\
\hline \multicolumn{2}{|r|}{ Redução do Produto } & $-0,75 \%$ & $-0,46 \%$ & $-1,79 \%$ & $-0,36 \%$ & $-0,33 \%$ & $-2,27 \%$ & $-0,93 \%$ & $-0,60 \%$ & $-3,20 \%$ \\
\hline
\end{tabular}

Fonte: Elaboração própria com base nos resultados da matriz insumo-produto de 2013. 


\section{Conclusão}

Este trabalho propôs-se a investigar os impactos sobre diferentes setores da cadeia da cana-de-açúcar e a eles relacionados por meio do método de insumoproduto. A inspiração para a realização do estudo se deve ao cenário conturbado que o setor canavieiro tem atravessado durante os últimos anos.

A cadeia da cana-de-açúcar tem como atividades principais a produção da matériaprima e a geração de importantes produtos para a economia nacional, especialmente $o$ açúcar e o etanol. 0 Brasil é o maior produtor mundial de cana-de-açúcar e essa produção vem crescendo nos últimos anos. Em 2012, o país produziu 32,4\% da cana-de-açúcar no mundo, o que garantiu sua representatividade como o maior produtor global. Contudo, observou-se uma queda em termos absolutos do PIB real do setor canavieiro e na participação do setor no PIB nacional entre os anos de 2010 e de 2014.

Em termos metodológicos, utilizou-se a abordagem de extração hipotética setorial a fim de quantificar as dependências intersetoriais. Vale ressaltar que o método utilizado apresenta limitações subjacentes, como a utilização de uma matriz não oficial e por limitações inerentes ao próprio método, ou seja, considera constante uma tecnologia única de produção. Entretanto, a abordagem de extração hipotética é uma forma de mensurar os linkages da economia e fornece meios de quantificar a interdependência entre os setores da economia.

Os principais resultados encontrados por meio da matriz de insumo-produto brasileira para o ano de 2013 revelam que as atividades do setor sucroalcooleiro têm fortes índices de ligação para trás, ou seja, o setor tem alta demanda por insumos da economia. Os setores ainda possuem multiplicadores da produção, da renda e do emprego que geram impacto na economia como um todo acima da média dos outros setores, esses resultados corroboram a teoria econômica especializada do setor sucroalcooleiro.

0 setor de fabricação e refino de açúcar apresentou resultados para o multiplicador da produção $(2,34)$ e para multiplicador da renda (tipo I - 2,30) superiores aos resultados encontrados para 2011. Por outro lado, esse setor mostrou uma queda no multiplicador do emprego (tipo I - 5,17) em 2013 quando comparado ao ano de 2011. No que tange as exportações, o setor perdeu participação em 1,03 pontos percentuais entre 2011 e 2013.

Por sua vez, o setor de fabricação de biocombustível apresentou em 2011 resultados para o multiplicador da produção e da renda (tipo I) e do emprego (tipo I) superiores aos de 2013. Entretanto, a participação desse setor nas exportações brasileiras aumentou em 0,27 pontos percentuais entre 2011 e 2013.

Os resultados do método de extração hipotética setorial mostram que o impacto em nível nacional surte maior efeito sobre a redução do produto total bruto no setor de fabricação e refino de açúcar (redução de 0,93\%). 0 açúcar é o principal produto fabricado pelo setor, sendo assim seria o que mais receberia o impacto caso esse 
desaparecesse da economia. Já o setor de fabricação de biocombustível reduziria a produção total da economia em 0,60\%, caso esse setor desaparecesse.

Esses resultados revelam grande importância em nível nacional principalmente para o setor de biocombustível que perdeu relativamente a capacidade de multiplicar a produção, a renda e o emprego entre os anos de 2011 e de 2013. Além disso, as exportações dos dois setores perderam participação no total das exportações brasileiras no período.

\section{Referências}

BACCHI, M. R. P. Interdependência dos mercados de gasolina $C$ e de álcool combustível no Estado de São Paulo. 6a․ Jornadas Interdisciplinarias de Estudos Agrários Y Agroindustriales, Buenos Aires, Argentina, 2009. Faculdade de Ciências Econômicas da Universidade de Buenos Aires.

BACCHI, M. R. P.; CALDARELLI, C. E. Impactos socioeconômicos da expansão do setor sucroenergético no Estado de São Paulo, entre 2005 e 2009. Nova Economia, v. 25, n. 1, p. 209-224, 2015. DOI: https://doi.org/10.1590/0103-6351/2168

BETARELLI JUNIOR, A. A.; PEROBELLI, F. S.; VALE, V. A. Estimação da Matriz de InsumoProduto de 2011 e Análise do Sistema Produtivo Brasileiro. Programa de Pós-Graduação em Economia, Universidade Federal de Juiz de Fora, Juiz de Fora, 2015.

CABRAL, J. A.; CABRAL, M. V. F.; OLIVEIRA, D. R. Análise do conteúdo tecnológico das exportações brasileiras sob a lógica estruturalista-kaldoriana. Nova Economia, v. 27, n. 2, 2017. DOI: https://doi.org/10.1590/0103-6351/3060

CABRAL, J. A.; PEROBELLI, F. S. Análise de decomposição estrutural para o setor de saúde brasileiro: 2000-2005. Pesquisa e Planejamento Econômico, v. 42, n. 3, p. 363402, 2012.

CELLA, G. The input-output measurement of interindustry linkages. Oxford Bulletin of Economics and Statistics, v. 46, n. 1, p. 73-84, 1984. DOI:

https://doi.org/10.1111/j.1468-0084.1984.mp46001005.x

CEPEA - Centro de Estudos Avançados em Economia Aplicada/ESALQ/USP.

Disponível em: <http://www.cepea.esalq.usp.br/>. Acesso em: dez. de 2015.

CEPEA. PIB Cadeias do Agronegócio. Piracicaba, 2017. Disponível em:

<https://www.cepea.esalq.usp.br/upload/kceditor/files/Relatorio\%20PIBAGR0\%2 0Cadeias_1_sem_2017_.pdf>. Acesso em 30 nov. 2017. 
CHAGAS, A. L. S. Três ensaios sobre o setor produtor de cana-de-açúcar no Brasil. 2009. 112f. Tese (Doutorado em Economia). Universidade de São Paulo, São Paulo, 2009.

CHAGAS, A. L. S.; TONETO JUNIOR, R.; AZZONI, C. R. Teremos que trocar energia por comida? Análise do impacto da expansão da produção de cana-de-açúcar sobre o preço da terra e dos alimentos. Revista Economia, 2008.

CNA - Confederação da Agricultura e Pecuária do Brasil. Disponível em: < http://www.canaldoprodutor.com.br/>. Acesso em: dez. de 2015.

CONAB - Companhia Nacional de Abastecimento. Disponível em: $<$ http://www.conab.gov.br/conteudos.php?a=1253\&ordem=produto\&Pagina_objc msconteudos=8\#A_objcmsconteudos $>$. Acesso em: dez. de 2015.

DIETZENBACHER, E.; LINDEN, J. A. van der; STEENGE, A. E. The regional extraction method: EC input-output comparisons. Economic Systems Research, v. 5, n. 2, p. 185-206, 1993. DOI: https://doi.org/10.1080/09535319300000017

DOMINGUES, E. P.; JUNIOR, A. A. B.; MAGALHÃES, A. S. Quanto vale o show?: Impactos econômicos dos investimentos da Copa do Mundo 2014 no Brasil. Estudos Econômicos (São Paulo), v. 41, n. 2, p. 409-439, 2011. DOI: https://doi.org/10.1590/S0101-41612011000200008

FAO - Food and Agriculture Organization of the United Nations. Disponível em: <http://faostat.fao.org/site/291/default.aspx>. Acesso em: dezembro de 2015.

GIGLIO, L. Análise dos impactos socioeconômicos da expansão do setor sucroenergético. 2015. 88f. Tese (Mestrado em Economia). Universidade de São Paulo, São Paulo, 2015.

GUILHOTO, J. J. M et al. Índices de ligação e setores chave na economia brasileira: 1959/80. Pesquisa e Planejamento Econômico, v. 2, n. 2, p. 287-314, 1994.

GUILHOTO, J. J. M. Análise de Insumo-Produto: Teoria e Fundamentos. University Library of Munich, Germany, 2011.

GUILHOTO, J. J. M.; SESSO FILHO, U. A. Estimação da Matriz Insumo-Produto Utilizando Dados Preliminares das Contas Nacionais: Aplicação e Análise de Indicadores Econômicos para o Brasil em 2005. Economia \& Tecnologia. UFPR/TECPAR. Ano 6, v. 23, Out, 2010. DOI: https://doi.org/10.5380/ret.v6i4. 26912 
GUILHOTO, J. J. M.; SESSO FILHO, U. A. Estimação da Matriz Insumo-Produto a Partir de Dados Preliminares das Contas Nacionais. Economia Aplicada. v. 9. n. 2. p. 277299, 2005.

HIRSCHMAN, A.O. The Strategy of Economic Development, Yale University Press, New Haven. 1958

HOFFMANN, R. Determinantes da Insegurança Alimentar no Brasil: Análise dos Dados da PNAD de 2004. Segurança Alimentar e Nutricional, UNICAMP, Campinas, SP, v. 15, n.1, p. 49-61, 2008. DOI: https://doi.org/10.20396/san.v15i1.1824

HOFFMANN, R. Segurança alimentar e produção de etanol no Brasil. Segurança Alimentar e Nutricional, UNICAMP, Campinas, SP, v. 13, n.2, p.01-05, 2006. DOI: https://doi.org/10.20396/san.v13i2.1827

IBGE - Instituto Brasileiro de Geografia e Estatística Disponível. Contas Nacionais Trimestrais. Disponível em:

<http://www.ibge.gov.br/home/estatistica/indicadores/pib/defaultcnt.shtm>. Acesso em: dez. de 2015.

IBGE- Instituto Brasileiro de Geografia e Estatística. Sistema IBGE de Recuperação Automática (SIDRA). Disponível em <http:// http://www.sidra.ibge.gov.br/>. Acesso em: dez. de 2015.

MILANEZ, Artur Yabe et al. $O$ déficit de produção de etanol no Brasil entre 2012 e 2015: determinantes, consequências e sugestões de política. BNDES Setorial, n. 35, p. 277-302, 2012.

MILLER, R. E.; LAHR, M. L. A taxonomy of extractions, in Lahr, M.L. and Miller, R.E. (Org.) Regional Science Perspectives in Economic Analysis: A Festschrift in Memory of Benjamin H. Stevens, Elsevier Science, Amsterdam, p. 407-441. 2001

MILLER, R.E.; BLAIR, P. D. Input-output analysis: foundations and extensions. Cambridge University Press, 2009. DOI: https://doi.org/10.1017/CB09780511626982

PAELINCK, J.; DE CAEVEL, J.; DEGUELDRE, J. Analyse quantitative de certaines phénomènes du développment régional polarisé: Essai de simulation statique d'itéraires de propogation. Bibliotheque de l'Institut de Science économique, v. 7, p. 341-387, 1965. 
PROTOCOLO AGROAMBIENTAL DO SETOR SUCROENERGÉTICO PAULISTA: dados consolidados das safras 2007/08 a 2013/14 - Dez. 2014. Disponível em: < <http://www.iea.sp.gov.br/Relat\%C3\%B3rioConsolidado1512.pdf>. Acesso em: Jan. 2016.

PEROBELLI, F. S. et al. Estrutura de interdependência inter-regional no Brasil: Uma análise espacial de insumo-produto para os anos de 1996 e 2002. Política e Planejamento Econômico, v. 40, n. 2, 2010.

PEREIRA, M. Z.; BASTOS, S. Q. A.; PEROBELLI, F. S. Análise sistêmica do setor de serviços no Brasil para o ano de 2005. Política e Planejamento Econômico, v. 43, n. 1, 2013.

RFA - Renewable Fuels Association. Disponível em: <http://www.ethanolrfa.org/>. Acesso em: Jan. de 2016.

SCHULTZ, S. Intersectoral comparisons as an approach to the identification of key sectors. Advances in Input/Output analysis, Ballinger, Cambridge, Mass, 1976.

SCOT CONSULTORIA. Disponível em: <https://www.scotconsultoria.com.br/>. Acesso em: dez. de 2015.

SHIKIDA, P. F. A.; MORAES, M. A. F. D. de; ALVES, L. R A. Agroindústria canavieira do Brasil: intervencionismo, desregulamentação e neocorporatismo. Revista de Economia e Agronegócio-REA, Viçosa (MG), v. 2, n. 3, p.361-382, jul./set. 2004.

SONG, Y.; LIU, C.; LANGSTON, C. Linkage measures of the construction sector using the hypothetical extraction method. Construction management and Economics, v. 24, n. 6, p. 579-589, 2006. DOI: https://doi.org/10.1080/01446190500435358

TOYOSHIMA, S.; FERREIRA, M. J. Encadeamentos do setor de transportes na economia brasileira. Planejamento e políticas públicas, n. 25, 2009.

UNICA - União da Indústria Canavieira de Cana-de-Açúcar. Estatísticas. Disponível em: < http://www.unica.com.br/canasat/>. Acesso em: jan. de 2016.

Recebido em 09.02.17

Aprovado em 13.09.18 


\section{Anexo 1: Índices de encadeamentos e dos graus de ligações dos setores econômicos brasileiros (2013)}

\begin{tabular}{|c|c|c|c|c|c|c|c|c|}
\hline \multirow{2}{*}{$\begin{array}{l}\text { Cod. } \\
\text { Setor }\end{array}$} & \multirow[t]{2}{*}{ Setores } & \multicolumn{5}{|c|}{ Indices de Hirshiman-Rasmussen } & \multicolumn{2}{|c|}{$\begin{array}{l}\text { Estatísticas de } \\
\text { Variabilidade }\end{array}$} \\
\hline & & $\mathbf{U j}$ & $\mathbf{U i}$ & Setores-Chave & Classi & icação & V.j & V.i \\
\hline 1 & Agricultura, inclusive o apoio à agricultura e a pós-colheita & 0,91 & 1,86 & - & - & FL & 6,56 & 3,15 \\
\hline 2 & Pecuária, inclusive o apoio à pecuária & 0,98 & 0,90 & - & - & - & 5,11 & 5,59 \\
\hline 3 & Produção florestal; pesca e aquicultura & 0,77 & 0,78 & - & - & - & 6,41 & 6,31 \\
\hline 4 & Extração de carvão mineral e de minerais não-metálicos & 1,01 & 0,70 & - & BL & - & 4,63 & 6,65 \\
\hline 5 & Extração de petróleo e gás, inclusive as atividades de apoio & 0,80 & 1,74 & - & - & FL & 6,70 & 3,04 \\
\hline 6 & Extração de minério de ferro, inclusive beneficiamentos e a aglomeração & 0,81 & 0,73 & - & - & - & 5,79 & 6,42 \\
\hline 7 & Extração de minerais metálicos não-ferrosos, inclusive beneficiamentos & 1,25 & 0,72 & - & BL & - & 3,94 & 6,80 \\
\hline 8 & Abate e produtos de carne, inclusive os produtos do laticínio e da pesca & 1,36 & 0,77 & - & BL & - & 3,67 & 6,50 \\
\hline 9 & Fabricação e refino de açúcar & 1,30 & 0,70 & - & BL & - & 3,66 & 6,74 \\
\hline 10 & Outros produtos alimentares & 1,26 & 0,95 & - & BL & - & 4,01 & 5,34 \\
\hline 11 & Fabricação de bebidas & 1,16 & 0,71 & - & BL & - & 4,37 & 7,08 \\
\hline 12 & Fabricação de produtos do fumo & 1,11 & 0,57 & - & BL & - & 4,27 & 8,24 \\
\hline 13 & Fabricação de produtos têxteis & 1,13 & 0,94 & - & BL & - & 5,01 & 5,97 \\
\hline 14 & Confecção de artefatos do vestuário e acessórios & 1,03 & 0,61 & - & BL & - & 4,59 & 7,74 \\
\hline 15 & Fabricação de calçados e de artefatos de couro & 1,11 & 0,62 & - & BL & - & 4,56 & 8,14 \\
\hline 16 & Fabricação de produtos da madeira & 1,05 & 0,76 & - & BL & - & 4,97 & 6,90 \\
\hline 17 & Fabricação de celulose, papel e produtos de papel & 1,16 & 1,07 & SETOR CHAVE & BL & FL & 4,58 & 4,98 \\
\hline 18 & Impressão e reprodução de gravações & 1,01 & 0,80 & - & BL & - & 4,85 & 6,08 \\
\hline 19 & Refino de petróleo e coquerias & 1,37 & 2,48 & SETOR CHAVE & BL & FL & 4,69 & 2,54 \\
\hline 20 & Fabricação de biocombustíveis & 1,28 & 0,67 & - & $\mathbf{B L}$ & - & 3,64 & 6,90 \\
\hline 21 & Fabricação de químicos orgânicos e inorgânicos, resinas e elastômeros & 1,17 & 1,80 & SETOR CHAVE & BL & FL & 4,95 & 3,20 \\
\hline 22 & Fabricação de defensivos, desinfestantes, tintas e químicos diversos & 1,13 & 1,08 & SETOR CHAVE & BL & FL & 4,42 & 4,63 \\
\hline 23 & Fabricação de produtos de limpeza, cosméticos/perfumaria e higiene pessoal & 1,19 & 0,62 & - & BL & - & 3,96 & 7,52 \\
\hline 24 & Fabricação de produtos farmoquímicos e farmacêuticos & 0,98 & 0,64 & - & - & - & 4,90 & 7,46 \\
\hline 25 & Fabricação de produtos de borracha e de material plástico & 1,14 & 1,23 & SETOR CHAVE & BL & FL & 4,64 & 4,31 \\
\hline 26 & Fabricação de produtos de minerais não-metálicos & 1,12 & 0,86 & - & BL & - & 4,52 & 5,92 \\
\hline 27 & Produção de ferro-gusa/ferroligas, siderurgia e tubos de aço sem costura & 1,17 & 1,22 & SETOR CHAVE & BL & FL & 4,47 & 4,31 \\
\hline 28 & Metalurgia de metais não-ferosos e a fundição de metais & 1,24 & 0,94 & - & BL & - & 4,31 & 5,66 \\
\hline 29 & Fabricação de produtos de metal, exceto máquinas e equipamentos & 1,10 & 1,04 & SETOR CHAVE & BL & FL & 4,51 & 4,78 \\
\hline 30 & Fabricação de equipamentos de informática, produtos eletrônicos e ópticos & 1,01 & 0,78 & - & BL & - & 5,41 & 6,97 \\
\hline 31 & Fabricação de máquinas e equipamentos elétricos & 1,14 & 0,80 & - & $\mathbf{B L}$ & - & 4,38 & 6,22 \\
\hline 32 & Fabricação de máquinas e equipamentos mecânicos & 1,10 & 0,92 & - & BL & - & 4,75 & 5,63 \\
\hline 33 & Fabricação de automóveis, caminhões e ônibus, exceto peças & 1,21 & 0,60 & - & BL & - & 3,97 & 7,96 \\
\hline 34 & Fabricação de peças e acessórios para veículos automotores & 1,14 & 0,89 & - & BL & - & 4,52 & 5,82 \\
\hline 35 & Fabricação de outros equipamentos de transporte, exceto veículos automotores & 1,07 & 0,69 & - & BL & - & 5,06 & 7,80 \\
\hline 36 & Fabricação de móveis e de produtos de indústrias diversas & 1,01 & 0,65 & - & BL & - & 4,67 & 7,24 \\
\hline 37 & Manutenção, reparação e instalação de máquinas e equipamentos & 0,99 & 1,14 & - & - & FL & 4,68 & 4,06 \\
\hline 38 & Energia elétrica, gás natural e outras utilidades & 1,16 & 1,71 & SETOR CHAVE & BL & FL & 5,66 & 3,83 \\
\hline 39 & Água, esgoto e gestão de resíduos & 0,86 & 0,81 & - & - & - & 5,41 & 5,70 \\
\hline 40 & Construção & 1,02 & 0,94 & - & BL & - & 4,95 & 5,41 \\
\hline 41 & Comércio e reparação de veículos automotores e motocicletas & 0,87 & 0,81 & - & - & - & 5,47 & 5,83 \\
\hline 42 & Comércio por atacado e a varejo, exceto veículos automotores & 0,85 & 3,57 & - & - & FL & 6,41 & 1,31 \\
\hline 43 & Transporte terrestre & 1,10 & 2,15 & SETOR CHAVE & BL & FL & 4,68 & 2,33 \\
\hline 44 & Transporte aquaviário & 1,04 & 0,70 & - & BL & - & 4,71 & 6,99 \\
\hline 45 & Transporte aéreo & 0,93 & 0,72 & - & - & - & 4,91 & 6,38 \\
\hline 46 & Armazenamento, atividades auxiliares dos transportes e correio & 0,87 & 1,33 & - & - & FL & 5,53 & 3,61 \\
\hline 47 & Alojamento & 0,90 & 0,63 & - & - & - & 5,08 & 7,25 \\
\hline 48 & Alimentação & 1,00 & 0,71 & - & - & - & 4,61 & 6,43 \\
\hline 49 & Edição e edição integrada à impressão & 1,02 & 0,63 & - & BL & - & 4,54 & 7,29 \\
\hline 50 & Atividades de televisão, rádio, cinema e gravação/edição de som e imagem & 0,98 & 1,13 & - & - & FL & 5,63 & 4,90 \\
\hline 51 & Telecomunicações & 1,03 & 1,06 & SETOR CHAVE & $\mathbf{B L}$ & FL & 5,17 & 5,02 \\
\hline 52 & Desenvolvimento de sistemas e outros serviços de informação & 0,79 & 0,92 & - & - & - & 6,12 & 5,22 \\
\hline 53 & Intermediação financeira, seguros e previdência complementar & 0,86 & 2,08 & - & - & FL & 6,13 & 2,46 \\
\hline 54 & Atividades imobiliárias & 0,62 & 1,03 & - & - & FL & 7,43 & 4,43 \\
\hline 55 & Atividades jurídicas, contábeis, consultoria e sedes de empresas & 0,80 & 1,81 & - & - & FL & 6,22 & 2,70 \\
\hline 56 & Serviços de arquitetura, engenharia, testes/análises técnicas e P \& D & 0,82 & 0,93 & - & - & - & 5,84 & 5,15 \\
\hline 57 & Outras atividades profissionais, científicas e técnicas & 1,13 & 1,19 & SETOR CHAVE & $\mathbf{B L}$ & FL & 4,18 & 3,97 \\
\hline 58 & Aluguéis não-imobiliários e gestão de ativos de propriedade intelectual & 0,79 & 0,94 & - & - & - & 5,90 & 4,94 \\
\hline 59 & Outras atividades administrativas e serviços complementares & 0,79 & 1,44 & - & - & FL & 5,93 & 3,24 \\
\hline 60 & Atividades de vigilância, segurança e investigação & 0,69 & 0,76 & - & - & - & 6,61 & 5,99 \\
\hline 61 & Administração pública, defesa e seguridade social & 0,78 & 0,74 & - & - & - & 5,89 & 6,19 \\
\hline 62 & Educação pública & 0,71 & 0,57 & - & - & - & 6,43 & 8,01 \\
\hline 63 & Educação privada & 0,80 & 0,64 & - & - & - & 5,72 & 7,18 \\
\hline 64 & Saúde pública & 0,81 & 0,56 & - & - & - & 5,67 & 8,22 \\
\hline 65 & Saúde privada & 0,86 & 0,61 & - & - & - & 5,88 & 8,21 \\
\hline 66 & Atividades artísticas, criativas e de espetáculos & 0,89 & 0,63 & - & - & - & 5,27 & 7,37 \\
\hline 67 & Organizações associativas e outros serviços pessoais & 0,93 & 0,70 & - & - & - & 4,94 & 6,51 \\
\hline 68 & Serviços domésticos & - & - & - & - & - & - & - \\
\hline
\end{tabular}

Fonte: Baterelli Junior, Perobelli e Vale (2015), atualizado para o ano de 2013. 
Anexo 2: Principais Resultados da Matriz Insumo-Produto (2013)

\begin{tabular}{|c|c|c|c|c|c|c|}
\hline $\begin{array}{l}\text { Cod. } \\
\text { Setor }\end{array}$ & $\begin{array}{l}\text { Multiplicador } \\
\text { de Produção }\end{array}$ & $\begin{array}{c}\text { Multiplicador } \\
\text { de Renda }\end{array}$ & $\begin{array}{c}\text { Multiplicador } \\
\text { de Renda }\end{array}$ & $\begin{array}{l}\text { Multiplicador } \\
\text { de Emprego }\end{array}$ & $\begin{array}{l}\text { Multiplicador } \\
\text { de Emprego }\end{array}$ & $\begin{array}{c}\% \\
\text { Exportações }\end{array}$ \\
\hline 1 & 1,63 & 1,98 & 2,75 & 1,19 & 1,34 & $11,10 \%$ \\
\hline 2 & 1,77 & 1,69 & 2,36 & 1,16 & 1,26 & $0,73 \%$ \\
\hline 3 & 1,38 & 1,76 & 2,45 & 1,16 & 1,24 & $0,11 \%$ \\
\hline 4 & 1,81 & 1,76 & 2,45 & 1,78 & 2,61 & $0,18 \%$ \\
\hline 5 & 1,44 & 2,04 & 2,84 & 10,07 & 19,23 & $4,57 \%$ \\
\hline 6 & 1,46 & 2,18 & 3,03 & 5,90 & 10,29 & $10,08 \%$ \\
\hline 7 & 2,24 & 2,44 & 3,39 & 4,10 & 6,60 & $0,73 \%$ \\
\hline 8 & 2,46 & 3,86 & 5,37 & 10,44 & 12,45 & $4,92 \%$ \\
\hline 9 & 2,34 & 2,30 & 3,20 & 5,17 & 6,65 & $3,18 \%$ \\
\hline 10 & 2,27 & 2,98 & 4,14 & 3,71 & 4,76 & $4,02 \%$ \\
\hline 11 & 2,08 & 2,97 & 4,13 & 4,37 & 6,42 & $0,37 \%$ \\
\hline 12 & 2,00 & 3,21 & 4,47 & 11,82 & 15,65 & $1,03 \%$ \\
\hline 13 & 2,03 & 1,89 & 2,63 & 1,81 & 2,31 & $0,24 \%$ \\
\hline 14 & 1,86 & 1,63 & 2,27 & 1,37 & 1,65 & $0,19 \%$ \\
\hline 15 & 1,99 & 1,78 & 2,48 & 1,78 & 2,35 & $1,00 \%$ \\
\hline 16 & 1,89 & 1,72 & 2,40 & 1,74 & 2,18 & $0,55 \%$ \\
\hline 17 & 2,09 & 2,46 & 3,42 & 4,11 & 6,14 & $2,23 \%$ \\
\hline 18 & 1,81 & 1,67 & 2,32 & 1,69 & 2,46 & $0,02 \%$ \\
\hline 19 & 2,46 & 10,78 & 14,99 & 72,28 & 115,17 & $3,04 \%$ \\
\hline 20 & 2,31 & 2,60 & 3,61 & 7,12 & 9,11 & $0,88 \%$ \\
\hline 21 & 2,10 & 3,42 & 4,76 & 8,84 & 14,28 & $2,27 \%$ \\
\hline 22 & 2,04 & 2,52 & 3,50 & 5,39 & 8,81 & $0,73 \%$ \\
\hline 23 & 2,13 & 2,61 & 3,63 & 3,16 & 4,59 & $0,35 \%$ \\
\hline 24 & 1,76 & 2,04 & 2,84 & 4,34 & 7,22 & $0,38 \%$ \\
\hline 25 & 2,05 & 1,96 & 2,72 & 2,45 & 3,75 & $0,99 \%$ \\
\hline 26 & 2,02 & 1,96 & 2,72 & 1,99 & 2,88 & $0,64 \%$ \\
\hline 27 & 2,11 & 2,77 & 3,86 & 6,31 & 10,30 & $3,26 \%$ \\
\hline 28 & 2,23 & 2,91 & 4,05 & 4,66 & 7,31 & $2,25 \%$ \\
\hline 29 & 1,98 & 1,78 & 2,47 & 1,80 & 2,69 & $0,75 \%$ \\
\hline 30 & 1,81 & 2,47 & 3,43 & 4,26 & 6,71 & $0,50 \%$ \\
\hline 31 & 2,06 & 2,11 & 2,94 & 3,04 & 4,93 & $1,07 \%$ \\
\hline 32 & 1,97 & 2,00 & 2,79 & 3,09 & 5,04 & $2,53 \%$ \\
\hline 33 & 2,18 & 3,58 & 4,98 & 9,39 & 15,21 & $3,08 \%$ \\
\hline 34 & 2,06 & 1,93 & 2,68 & 2,97 & 4,96 & $1,98 \%$ \\
\hline 35 & 1,92 & 1,94 & 2,70 & 3,21 & 5,53 & $4,31 \%$ \\
\hline 36 & 1,82 & 1,80 & 2,50 & 1,66 & 2,21 & $0,38 \%$ \\
\hline 37 & 1,78 & 1,80 & 2,50 & 1,59 & 2,25 & $0,42 \%$ \\
\hline 38 & 2,09 & 3,13 & 4,36 & 6,98 & 12,19 & $0,01 \%$ \\
\hline 39 & 1,54 & 1,45 & 2,02 & 1,42 & 2,01 & $0,01 \%$ \\
\hline 40 & 1,84 & 1,80 & 2,51 & 1,53 & 2,02 & $0,48 \%$ \\
\hline 41 & 1,56 & 1,43 & 1,99 & 1,22 & 1,58 & $1,19 \%$ \\
\hline 42 & 1,53 & 1,37 & 1,91 & 1,25 & 1,64 & $9,26 \%$ \\
\hline 43 & 1,97 & 1,68 & 2,34 & 1,48 & 2,03 & $1,64 \%$ \\
\hline 44 & 1,87 & 1,82 & 2,54 & 2,69 & 4,83 & $0,42 \%$ \\
\hline 45 & 1,68 & 1,79 & 2,49 & 3,94 & 7,12 & $0,74 \%$ \\
\hline 46 & 1,57 & 1,42 & 1,98 & 1,67 & 2,72 & $1,06 \%$ \\
\hline 47 & 1,62 & 1,33 & 1,85 & 1,33 & 1,80 & $0,76 \%$ \\
\hline 48 & 1,79 & 1,67 & 2,32 & 1,34 & 1,60 & $0,56 \%$ \\
\hline 49 & 1,84 & 1,64 & 2,28 & 2,01 & 3,14 & $0,09 \%$ \\
\hline 50 & 1,76 & 1,78 & 2,48 & 2,63 & 4,24 & $0,01 \%$ \\
\hline 51 & 1,84 & 3,09 & 4,30 & 6,33 & 9,73 & $0,11 \%$ \\
\hline 52 & 1,42 & 1,32 & 1,84 & 1,61 & 2,77 & $0,15 \%$ \\
\hline 53 & 1,54 & 1,57 & 2,18 & 2,89 & 5,75 & $1,61 \%$ \\
\hline 54 & 1,11 & 3,16 & 4,39 & 1,91 & 2,70 & $0,52 \%$ \\
\hline 55 & 1,44 & 1,39 & 1,93 & 1,42 & 2,12 & $1,45 \%$ \\
\hline 56 & 1,48 & 1,39 & 1,93 & 1,51 & 2,39 & $2,46 \%$ \\
\hline 57 & 2,03 & 2,94 & 4,09 & 2,29 & 3,35 & $0,26 \%$ \\
\hline 58 & 1,42 & 1,43 & 1,99 & 1,49 & 2,22 & $0,45 \%$ \\
\hline 59 & 1,43 & 1,21 & 1,69 & 1,18 & 1,63 & $1,09 \%$ \\
\hline 60 & 1,24 & 1,08 & 1,51 & 1,09 & 1,60 & $0,00 \%$ \\
\hline 61 & 1,40 & 1,18 & 1,64 & 1,46 & 2,83 & $0,30 \%$ \\
\hline 62 & 1,28 & 1,09 & 1,52 & 1,21 & 2,15 & $0,01 \%$ \\
\hline 63 & 1,44 & 1,16 & 1,62 & 1,14 & 1,61 & $0,01 \%$ \\
\hline 64 & 1,46 & 1,18 & 1,64 & 1,46 & 2,55 & $0,00 \%$ \\
\hline 65 & 1,54 & 1,39 & 1,94 & 1,40 & 1,93 & $0,00 \%$ \\
\hline 66 & 1,59 & 1,37 & 1,91 & 1,17 & 1,43 & $0,27 \%$ \\
\hline 67 & 1,67 & 1,49 & 2,07 & 1,24 & 1,52 & $0,01 \%$ \\
\hline 68 & - & - & 1,39 & - & 1,18 & $0,00 \%$ \\
\hline Média & 1,80 & 2,12 & 2,95 & 4,15 & 6,40 & - \\
\hline
\end{tabular}

Fonte: Adaptado de Batarelli Junior, Perobelli e Vale (2015) e atualizado para o ano de 2013. 